\title{
Supplementing goat kids with coconut medium chain fatty acids in early life influences growth and rumen papillae development until 4 months after supplementation but effects on in vitro methane emissions and the rumen microbiota are transient
}

\author{
Sieglinde Debruyne, ${ }^{*, \dagger}$ Alexis Ruiz-González, ${ }^{*}$ Einar Artiles-Ortega, ${ }^{*} \S$ Bart Ampe ${ }^{\dagger}$ \\ Wim Van Den Broeck, ${ }^{\ddagger}$ Ellen De Keyser, ${ }^{\#}$ Leen Vandaele, ${ }^{\dagger}$ Karen Goossens, ${ }^{\dagger}$ and Veerle Fievez ${ }^{*, 1}$
}

*Laboratory for Animal Nutrition and Animal Product Quality, Department of Animal Production, Faculty of Bioscience Engineering, Ghent University, Coupure Links 653- Block F, 9000 Ghent, Belgium; 'Department of Animal Sciences and Aquatic Ecology, Flanders Research Institute for Agriculture, Fisheries and Food (ILVO), Animal Sciences Unit, Scheldeweg 68, Melle 9090, Belgium;'Department of Veterinary Medicine and Zootechnics, Faculty of Agricultural Sciences, Central University "Marta Abreu" de Las Villas, Carretera a Camajuaní km 51/2, Santa Clara 54830, Cuba; "Department of Morphology, Faculty of Veterinary Medicine, Ghent University, Salisburylaan 133, Merelbeke 9820, Belgium; \#Flanders Research Institute for Agriculture, Fisheries and Food (ILVO), Plant Sciences Unit, Caritasstraat 39, Melle 9090, Belgium

\begin{abstract}
The aim of this study was to investigate the methane $\left(\mathbf{C H}_{4}\right)$ reducing potential of a combination of prenatal and/or postnatal treatment with coconut oil medium chain fatty acids (CO MCFA) in goat kids. The hypothesis is that influencing rumen function during early life has more chances for success than in the adult life, related to the resilience of the mature rumen microbiota. Forty-eight pregnant does were split
\end{abstract}

Financial support for this research has been provided within the frame of the FACCE JPI Multi-partner Call on Agricultural Greenhouse Gas Research (RumenStability). Sieglinde Debruyne received a PhD grant from Flanders Innovation \& Entrepreneurship (VLAIO). Alexis RuizGonzález received a $\mathrm{PhD}$ grant from CONACyT (The National Council for Science and Technology, Mexico). Einar Artiles-Ortega received a PhD grant from the Special Research Fund of Ghent University. This work was further supported by a STSM Grant from the COST Action FA1302 (www.methagene.eu). Special thanks to David Yañez-Ruíz (CSIC, Spain) for practical training at his research institute. Thanks to lab technicians Charlotte Melis for performing batch incubations, Lobke Debels for preparing rumen wall slides for histological work and Laurence Desmet for assistance and guidance during the microbial work. Thanks to Emily McGovern (Teagasc) for her hints in optimization of the RNA extraction protocol. Thanks to BSc and MSc students Liesbeth Rommelaere and Wanda Pollet for practical help in the lab and during the in vivo trial. Also, thanks to Dorien Van Wesemael (ILVO/Ghent University) for internal review of the manuscript.

${ }^{1}$ Corresponding author: Veerle.Fievez@ugent.be

Received June 12, 2017.

Accepted February 23, 2018. into two experimental groups: treated does $(\mathbf{D}+)$ received $40 \mathrm{~g} / \mathrm{d}$ of CO MCFA in a test compound feed, while control does (D-) received a control compound feed, during the last $3 \mathrm{wk}$ of gestation. Twin kids from 10 does of each group were split up into a treated $(\mathbf{K}+)$ and nontreated $\left(\mathbf{K}^{-}\right)$group, resulting in four experimental groups: $\mathrm{D}+\mathrm{K}+$, $\mathrm{D}+\mathrm{K}-, \mathrm{D}-\mathrm{K}+$, and $\mathrm{D}-\mathrm{K}-$. The $\mathrm{K}+$ kids received $1.8 \mathrm{~mL} / \mathrm{d}$ of CO MCFA from birth until 2-wk postweaning (11 wk). Irrespective of treatment, the experimental rearing conditions resulted in absence of rumen protozoa at all sampling times, assessed by quantitative PCR (qPCR). In vitro incubations with rumen fluid at 4 wk old showed $82 \%$ lower $\mathrm{CH}_{4}$ production of inoculum from $\mathrm{D}+\mathrm{K}+$ kids compared to $\mathrm{D}-\mathrm{K}-$ kids $(P=0.01)$. However, this was accompanied by lower total volatile fatty acids (tVFA) production $(P=0.006)$ and higher hydrogen accumulation $(P=0.008)$. QPCR targeting the mcrA and rrs genes confirmed a lower abundance of total methanogens $(P<0.02)$ and total eubacteria $(P=0.02)$ in $\mathrm{D}+\mathrm{K}+$ kids at $4 \mathrm{wk}$ old. Methanogenic activity, as assessed by $m c r A$ expression by RT-qPCR, was also lower in these kids. However, activity did not always reflect methanogen abundance. At 11 and 28 wk old, prenatal and postnatal effects on in vitro fermentation and rumen microbiota disappeared. Nevertheless, lower milk replacer intake in the first 4 wk resulted in reduced $\mathrm{BW}$ in $\mathrm{K}+$ kids, persisting until 28 wk of age. Additionally, differences assigned to postnatal treatment were found in papillae density, width, and length in 
different areas of the rumen, recorded at $28 \mathrm{wk}$ old. Conclusion: prenatal and postnatal supplementation with $\mathrm{CO}$ MCFA reduced in vitro $\mathrm{CH}_{4}$ emissions until 4 wk old by depressing methanogen abundance and activity but at the expense of rumen fermentation and eubacterial abundance.
Unfortunately, daily gain of $\mathrm{K}+$ kids was suppressed. Some rumen papillae characteristics differed at 28 wk old due to postnatal treatment which ended at $11 \mathrm{wk}$ old, indicating rumen papillary development can be affected by the early-life nutritional circumstances.

Key words: goat kids, in vitro enteric methane, medium chain fatty acids, prenatal/postnatal programming, (RT-) qPCR, rumen papillae

(C) The Author $(s)$ 2018. Published by Oxford University Press on behalf of the American Society of Animal Science. All rights reserved. For permissions, please e-mail: journals.permissions@oup.com. J. Anim. Sci. 2018.96:1978-1995 doi: $10.1093 /$ jas/sky070

\section{INTRODUCTION}

Nearly $50 \%$ of global greenhouse gas emissions coming from livestock farming is methane $\left(\mathbf{C H}_{4}\right)$ (Gerber et al., 2013). Microbial fermentation in the rumen is the main contributor to these $\mathrm{CH}_{4}$ emissions. Coconut oil $(\mathbf{C O})$, rich in medium chain fatty acids (MCFA) (Hristov et al., 2009), is a promising $\mathrm{CH}_{4}$-reducing feed supplement (Machmüller 2006). In the rumen, it might act as a defaunating agent (Newbold and Chamberlain, 1988), affecting methanogens indirectly (Finlay et al., 1994) but it also might affect methanogens directly (Machmüller et al., 2003). However, the $\mathrm{CH}_{4}$-reducing effects of $\mathrm{CO}$ have not yet been proven to be persistent, in part due to generally short-term studies, while microbial adaptation is likely to occur given the resilient microbial community in the mature rumen (Weimer 2015). Manipulating rumen function in early life (EL) could modify the microbiota in a targeted and permanent manner, using less supplement, while potentially resulting in long-lasting $\mathrm{CH}_{4}$ reductions (Yáñez-Ruiz et al., 2015). The rapid initial colonization of the rumen (Jami et al., 2013; Rey et al., 2014) illustrates the need for early interventions in very young animals for manipulation of these processes. Recent studies (Yáñez-Ruiz et al., 2010; Abecia et al., 2013) explored early postnatal nutritional interventions, while fewer studies also investigated the potential of prenatal programming (De Barbieri et al., 2015a, 2015b). Accordingly, we hypothesized that supplementation with CO MCFA in EL could result in persistent lower $\mathrm{CH}_{4}$ production, through suppressing effects on the rumen microbiota. As a change in rumen fermentation is expected, this suggests rumen papillae development could be affected as well (Malhi et al., 2013). These changes could persist after ceasing the treatment.

\section{MATERIALS AND METHODS}

The experiment was approved by the ethical committee of the Faculty of Veterinary Medicine (Ghent University, Belgium, approval number EC2015/12) and the experiment was conducted at the experimental stables of the Laboratory for Animal Nutrition and Product Quality (Melle, Belgium). All persons involved with animal care and sampling had previously obtained the necessary FELASA (Federation of European Laboratory Animal Science Associations) certificates.

\section{Animals, Treatments, and Experimental Design}

Prenatal treatment. A flock of 48 synchronized pregnant dairy goats (Saanen) from a commercial farm (Zele, Belgium) was randomly split into two groups (D-, control and $\mathbf{D}+$, treated) for the last $3 \mathrm{wk}$ of gestation. Both groups were offered $2 \times 0.5 \mathrm{~kg} / \mathrm{d}$ of a compound feed, which only differed in type of oil included (at $40 \mathrm{~g} / \mathrm{kg} \mathrm{DM}$ ), i.e. palm oil for the D- group and unesterified MCFA from CO (AVEVE, Merksem, Belgium) for the D+ group. Both concentrates were iso-energetic. Table 1 shows the fatty acid composition of the palm oil and unesterified MCFA product from $\mathrm{CO}$ used in the compound feed. All does were fed the same roughage mixture: prewilted grass silage (ad libitum) from the beginning of the dry period ( $6 \mathrm{wk}$ before parturition) until $2 \mathrm{wk}$ before parturition, followed by a mixture of prewilted grass silage, maize silage, and sugar beet pulp (200/720/80 g/kg DM respectively, ad libitum) during the last 2 wk of gestation.

Postnatal treatment. Within each group, the objective was to obtain 10 does that gave birth to preferably two male kids. This objective could not be obtained within this flock, and hence four does with 
Table 1. Fatty acid composition of palm oil (control product) and unesterified MCFA product from coconut oil used in compound feeds of does and supplemented to the $\mathrm{K}+$ kids (MCFA from coconut oil only)

\begin{tabular}{lcr}
\hline \hline Item & MCFA from coconut oil & Palm oil \\
\hline Fatty acid, g/kg & & \\
C8:0 & 75 & ND \\
C10:0 & 60 & ND \\
C12:0 & 470 & 2 \\
C14:0 & 185 & 10 \\
C16:0 & 93 & 415 \\
C18:0 & 30 & 43 \\
C18:1 $n-9$ & 70 & 368 \\
C18:2 $n-6$ & 17 & 99 \\
C18:3 $n-3$ & ND & 34 \\
\hline
\end{tabular}

$\mathrm{ND}=$ not detected

one male and one female kid were used. Also, two individual kids from separate $\mathrm{D}+$ does, but sharing the same sire, were used by lack of multiple kids being born from the group of 48 does available for this experiment. All 40 kids used in the experiment were born within a time frame of 7 days, and from a multiparous dam. The two kids from each doe were taken up into the trial and randomly assigned to a control $(\mathbf{K}-)$ or treated $(\mathbf{K}+)$ kids group. Four experimental conditions were created by combining prenatal and/or postnatal treatment: $\mathrm{D}-\mathrm{K}-$ $(n=10), \mathrm{D}-\mathrm{K}+(n=10), \mathrm{D}+\mathrm{K}-(n=10), \mathrm{D}+\mathrm{K}+$ $(n=10)$. One kid of the $\mathrm{D}+\mathrm{K}-$ group died at 21 $\mathrm{d}$ of age due to congenital heart failure. Postnatal treatment, initiated at the commercial farm, started within 6 hours after birth and continued until 2-wk postweaning (11 wk old; Figure 1). Dose of MCFA for the newborn kids was deducted from doe's dose, based on estimated BWs (doe: $40 \mathrm{~g} / \mathrm{d}$ at $75 \mathrm{~kg} \mathrm{BW}$; Kid: $1.6 \mathrm{~g}$ or $1.8 \mathrm{~mL} / \mathrm{d}$ at $3 \mathrm{~kg} \mathrm{BW})$. The coconut MCFA product (liquefied in glass pots using a hot water bath $)(2 \times 0.9 \mathrm{~mL} / \mathrm{d})$ was squirted with a small syringe into the back of the mouth of the kid, twice a day before milk feeding. BW was recorded before morning feeding every 2 wk until weaning (completed at $9 \mathrm{wk}$ for all kids), at the end of the indoor stable period (13 wk) and at euthanasia (28 wk). Kids were sampled for rumen fluid at $4 \mathrm{wk}, 11 \mathrm{wk}$ (oesophageal tube), and $28 \mathrm{wk}$ of age (after euthanasia). At 28 wk old, rumen wall samples were collected for analysis of papillae development.

\section{Diets and Housing}

Does stayed at the commercial farm after kidding, while kids stayed there for $1 \mathrm{~d}$, separated from the dam. Kids received mixed unpasteurized colostrum three times on day 1 from does that recently gave birth and were housed on straw under a heat lamp. Kids were transported at day 2 to the experimental stable. From birth until 13 wk old, kids were housed in pairs of the same experimental condition in pens equipped with rubber mats and bedded with straw $(1.8 \times 2.2 \mathrm{~m}$; width $\times$ length $)$. The pens were constructed to avoid physical contact between the neighboring kids during the first wk. Kids were fed colostrum from the second and third milking of all does that recently gave birth, twice a day during the first $2 \mathrm{~d}$ at the stable. Afterward, milk replacer (200 g/L, Denkamilk Capri Ovi, Denkavit, Voorthuizen, the Netherlands) was fed by bottle twice a day (08:30 $\mathrm{h}$ and 16:00 h) until kids were able to drink in pairs from a suckling bucket (per feeding max. 2 L/2 kids). From 6 wk onward, milk powder concentration was lowered from $200 \mathrm{~g} / \mathrm{L}$ to $175 \mathrm{~g} / \mathrm{L}$. At $7 \mathrm{wk}$, the amount of milk replacer was reduced to $1 \mathrm{~L} / 2$ kids per feeding and at $8 \mathrm{wk}$, feeding frequency was lowered to once daily $(08: 30 \mathrm{~h})$, until kids were weaned at 9 wk old. Concentrate (Capri 181, AVEVE, Merksem, Belgium) was provided twice a day from $1 \mathrm{wk}$ of age onward (per feeding: $50 \mathrm{~g} / 2$ kids at week 1 up to $\max .500 \mathrm{~g} / 2$

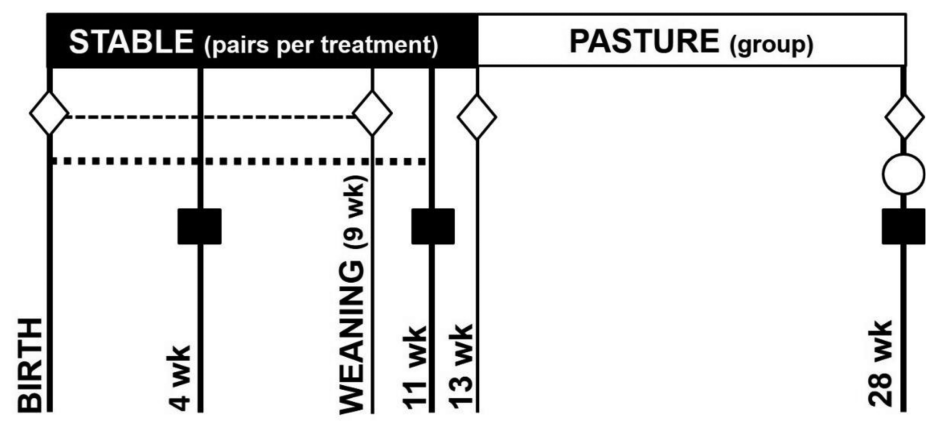

Figure 1. Sampling and data collection schedule of goat kids. Kids were weighed $(\diamond)$ from birth until weaning every 2 wk (----), at the end of the stable period and at $28 \mathrm{wk}$ old. The bold dashed line (- - - ) indicates postnatal treatment period. At three ages (4 wk, $11 \mathrm{wk}, 28 \mathrm{wk})$, and rumen fluid were sampled (ם). At 28 wk old, additional rumen wall samples (o) were collected after euthanasia to assess papillae development. 
kids). Kids had ad libitum access to water and hay during the whole indoor stable period. The treatment period lasted until $2 \mathrm{wk}$ post weaning (11 wk old), and kids were kept indoors until 13 wk old. Afterward, they were placed outside on a pasture $(67 \times 50 \mathrm{~m})$ to graze in group. Female kids were physically separated from males during the pasture period. On the pasture, all kids were daily supplemented $(08: 30 \mathrm{~h})$ with concentrate (max. $500 \mathrm{~g} / \mathrm{kid})$ until the end of the trial ( $28 \mathrm{wk}$ ). Hay was supplemented when fresh grass supply from the pasture was not sufficient.

\section{Rumen Fluid Collection and Euthanasia}

At the ages of 4 and 11 wk old, rumen fluid was sampled, after a night of fasting and before morning feeding through esophageal tubing using a self-made plastic transparent tube (outer diameter $15 \mathrm{~mm}$ ) connected to a plastic erlenmeyer and a vacuum pump. A volume of $30-\mathrm{mL}$ fluid and digesta was collected per kid for subsequent in vitro incubations the same day. Materials were rinsed with hot water between sampling different kids and a 70\% ethanol in water solution was used to disinfect. At approximately 28 wk old, kids were brought back into the stable on four different days (in the afternoon) within a 2-wk period, in three groups of 10 and one group of 9 kids. Kids were fasted overnight in the stable, with access to water, and euthanized the next day between 08:30 $\mathrm{h}$ and 09:00 h. First Xylazine $(4 \mathrm{~mL} /$ kid intravenously) was given to sedate the kids, then Nembutal (Release, $10 \mathrm{~mL} / \mathrm{kid}$ ) was used to euthanize. One group of nine kids (one $\mathrm{D}+\mathrm{K}+$, two $\mathrm{D}+\mathrm{K}-$, three $\mathrm{D}-\mathrm{K}+$, and three $\mathrm{D}-\mathrm{K}-$ kids) was removed from the data set for the incubations at $28 \mathrm{wk}$ because of a feeding error on the day of euthanasia, which resulted in two kids with clear signs of acute rumen acidosis (rumen pH: 4.15 and 4.65). As results of in vitro incubations are largely influenced by feed remainders in the rumen inoculum, the statistical analysis for these in vitro fermentation parameters was done with the remaining 30 kids which were correctly fasted overnight before euthanasia $(\mathrm{D}+\mathrm{K}+$ $n=9, \mathrm{D}+\mathrm{K}-n=7, \mathrm{D}-\mathrm{K}+n=7, \mathrm{D}-\mathrm{K}-n=7)$. Within 1.5 hours after euthanasia, kids were weighed and exsanguinated, the rumen was dissected and opened and approximately $100 \mathrm{~mL}$ of rumen fluid was collected by squeezing the fibrous contents. In accordance to sampling at 4 and $11 \mathrm{wk}$, polypropylene tubes $(15 \mathrm{~mL})$ were completely filled with rumen fluid before closing with a screw cap, to minimize air contamination. Tubes were stored in thermos flasks filled with warm water for transportation to the lab, at walking distance ( $3 \mathrm{~min}$ ) from the stable. Additionally, for all kids at all three sampling times, three aliquots of approximately $1.5 \mathrm{~mL}$ of rumen fluid were pipetted into screw cap cryovials and immediately snap-frozen with liquid nitrogen (in the stable). The cryovials were then stored at $-80^{\circ} \mathrm{C}$ until later microbial analysis.

\section{In Vitro Incubations ( $\mathrm{CH}_{4}$ and Rumen Fermentation)}

In vitro batch incubations with fresh rumen fluid (Vlaeminck et al., 2014) were performed within 15 min after sampling. Rumen fluid was first sieved (1 $\mathrm{mm}$ pore size) and mixed with a phosphate-bicarbonate buffer at a ratio of $1: 4$, under constant $\mathrm{CO}_{2}$ flushing. The $\mathrm{pH}$ was measured before and after addition of the buffer. Then, $14 \mathrm{~mL}$ (at 4 and $11 \mathrm{wk}$, due to a limited amount of inoculum which could be retrieved at these ages) or $24 \mathrm{~mL}$ (at $28 \mathrm{wk}$ ) of the mixture was injected into a glass penicillin flask (volume $120 \mathrm{~mL}$ ), closed with a rubber stopper. Prior to inoculum-buffer addition, flaks had been supplemented with $150 \mathrm{mg}$ (4 and $11 \mathrm{wk}$ ) or $250 \mathrm{mg}$ ( $28 \mathrm{wk}$ ) of dried grass silage, wetted by $1 \mathrm{~mL}$ of distilled water and air-tight closed. Flasks were then flushed with $\mathrm{CO}_{2}$ to create anaerobic conditions. Overpressure of gas was released and $1 \mathrm{~mL}$ of ethane $\left(\mathrm{C}_{2} \mathrm{H}_{6}\right)$ was injected as an internal standard for later gas measurements. Flasks were incubated in duplicate for $4 \mathrm{~h}$ and $24 \mathrm{~h}\left(39^{\circ} \mathrm{C}\right)$ on a shaking platform to investigate differences in speed of fermentation processes by the different inocula $(4 \mathrm{~h})$ and total potential to ferment the added substrate $(24 \mathrm{~h})$ by the rumen micro-organisms in the inocula. After incubation, flasks were put for $5 \mathrm{~min}$ in an ice bath to stop fermentation processes. Built-up gas overpressure was released and gas composition $\left(\mathrm{CH}_{4}, \mathrm{H}_{2}\right.$, $\mathrm{CO}_{2}, \mathrm{C}_{2} \mathrm{H}_{6}$ ) was measured by micro gas chromatograph (3000 micro-GC, Agilent, USA) (Hassim et al., 2010). A standard series of eight flasks, first flushed with $\mathrm{CO}_{2}$ and injected with known volumes of $\mathrm{H}_{2}, \mathrm{CH}_{4}$, and $\mathrm{C}_{2} \mathrm{H}_{6}$, were also analyzed for each incubation run. Areas were recovered and regression curves were fitted based on $\mathrm{CH}_{4} / \mathrm{C}_{2} \mathrm{H}_{6}$ and $\mathrm{H}_{2} /$ $\mathrm{C}_{2} \mathrm{H}_{6}$ ratios from the standard series flasks, which was used to calculate the net production of $\mathrm{CH}_{4}$ and $\mathrm{H}_{2}$ accumulation in each flask. Average values were calculated from duplicate flasks. Volatile fatty acid (VFA) analysis (C2:0, C3:0, iso-C4:0, $\mathrm{C} 4: 0$, iso-C5:0, C5:0, C6:0) of incubated rumen fluid was performed (Gadeyne et al., 2015). Also nonincubated fresh rumen samples were analyzed 
(blanks) and these VFA concentrations were used to calculate net production of VFA in the incubated flasks.

\section{Rumen Wall Sampling}

The reticulum, rumen, and omasum were dissected together and weighed full, after which the rumen was separated. The rumen was opened with an incision of approximately $15 \mathrm{~cm}$ starting from the dorsal side of the esophagus crossing the dorsal sac. After sampling of rumen content for in vitro incubations, the remaining rumen content was discarded. The empty rumen was flushed with tap water to remove particles and then weighed. After this, the rumen was presented on a table with the esophageal opening pointing to the left. The inner rumen wall was exposed by further cutting the rumen open over the left lateral side. Four anatomical areas were selected for papillae development analysis: (1) the ruminal atrium, (2) the ventral sac, (3) the caudodorsal blind sac, and (4) the caudoventral blind sac (Figure 2). A patch of $3 \times 3 \mathrm{~cm}$ was cut from each of the four areas and cleaned carefully with distilled water. Patches were immediately pinned on cardboard pieces with needles and immersed in glass pots $(150 \mathrm{~mL})$ filled with phosphate-buffered $4 \%$ formaldehyde solution ( $\mathrm{pH}$ 7.4) for histomorphometric analysis.

\section{Histological Evaluation and Histomorphometry of Rumen Wall Samples}

On the same day of sampling, rumen wall samples were analyzed for papillae density $\left(\right.$ number $\left./ \mathrm{cm}^{2}\right)$

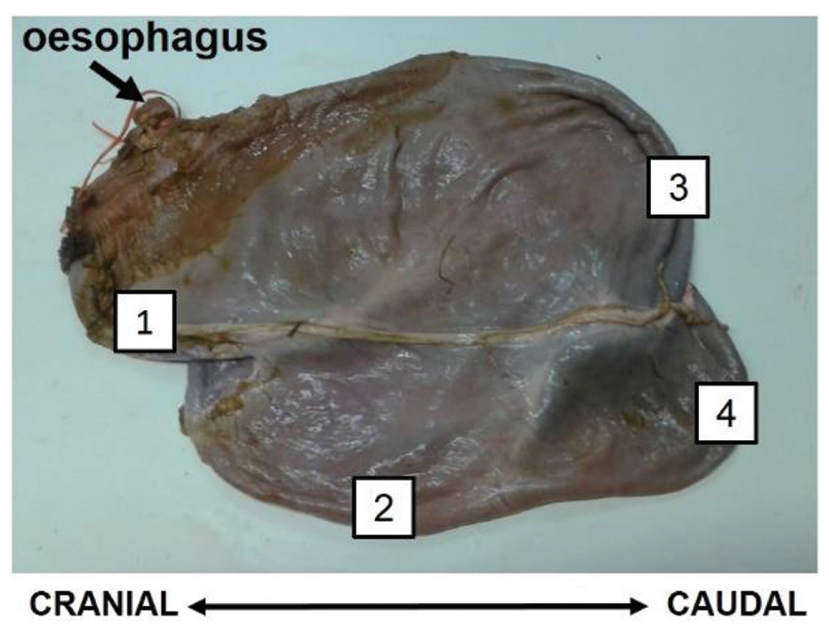

Figure 2. Rumen wall sampling areas. 1: bottom of the ruminal atrium 2: bottom of ventral sac, 3: caudal central part of dorsal blind sac, 4: caudal central part of ventral blind sac. by stereomicroscopy (Olympus SZX7, Olympus, Berchem, Belgium) (power objective lens: $8 \times$ ), using the "forbidden lines method" (Gundersen 1977). Samples were further left to fixate in phosphate-buffered 4\% formaldehyde solution $(\mathrm{pH} 7,4)$ for $24 \mathrm{~h}$. Afterward, $1 \mathrm{~cm}^{2}$ was cut from the sample and divided into two subsamples of $0.5 \mathrm{~cm}^{2}$. Subsamples were placed in fixating cassettes and flushed with tap water to remove formaldehyde from the tissue. Next, fixating cassettes were put in a tissue processor (Microm STP420D, Fisher Scientific, Loughborough, UK) for dehydrating, clearing, and paraffin infiltration (Böck and Romeis 1989). Sections $(8 \mu \mathrm{m})$ were made from the paraffin-imbedded subsamples using a microtome (Microm HM 360 Cool-cut, Thermo Fisher Scientific, Waltham, MA, USA) and placed on a glass microscope slide. Paraffin was then removed from the section by immersing the glass slide in xylene, decreasing alcohol series and distilled water (Böck and Romeis 1989), and stained with hematoxylin and eosin (H\&E). Tissue samples were further preserved by adding artificial resin (DPX [mixture of distyrene, a plasticizer, and xylene]) to the section, sealed with a glass coverslip and left to dry. Morphometric analysis of sections was performed using light microscopy (Olympus BX-OCB, Olympus, Berchem, Belgium) (power objective lens: 4 or $10 \times$ depending on the sample). For each rumen area of each goat, length from base to tip and width of the base from 10 papillae (e.g. 5 papillae from each subsample) were measured using image analysis software (Olympus CellSense Dimension, Olympus, Berchem, Belgium). Total surface area of papillae per square centimeter mucosa (TSA) was determined as length $\times$ width $\times 2 \times$ papillae density (Ragionieri et al., 2016).

\section{Total RNA and DNA Extraction From Rumen Fluid}

Approximately $1 \mathrm{~mL}$ of frozen rumen fluid and digesta, snap-frozen and stored in cryotubes under $-80^{\circ} \mathrm{C}$ until processing, was ground with a cooled pestle under addition of liquid nitrogen. For total RNA extraction, between 70 and $90 \mathrm{mg}$ of ground sample was weighed and stored in Eppendorf tubes on liquid nitrogen, along with $0.3 \mathrm{~g}$ zirconia-silica beads (diameter $0.1 \mathrm{~mm}$, Lab Services, Breda, The Netherlands). At the same time, between 200 and $220 \mathrm{mg}$ of ground sample and $0.8 \mathrm{~g}$ zirconia-silica beads (diameter $0.1 \mathrm{~mm}$ ) were stored at $-80^{\circ} \mathrm{C}$ for subsequent DNA extraction. The RNA extraction protocol was adapted from the Qiagen RNeasy Plus Mini kit (Qiagen Benelux B.V., Antwerp, Belgium). 
This consisted of initial lysis (lysis buffer and $\beta$-mercapto-ethanol) and homogenization (bead beating at $30 \mathrm{~Hz}$ for $2 \times 1 \mathrm{~min}$ with $30 \mathrm{~s}$ of rest in between; Retsch Tissue Lyser, Qiagen Benelux B.V.), removal of genomic DNA by gDNA eliminator columns, binding of total RNA to RNeasy Mini spin columns, washing and elution in $30 \mu \mathrm{L}$ of RNase-free water. The Nucleospin RNA Kit (Filter Service S.A., Eupen, Belgium), containing an on-column DNase incubation step, was subsequently used for further clean-up of RNA. Finally total RNA was eluted in $30 \mu \mathrm{L}$ R Nase-free water. Nucleic acid concentrations, 260/280 ratios, 260/230 ratios were measured and contamination assessment was done using Nanodrop (ND1000 V3.8.1, Wilmington, USA) and RNA quality was checked for a number of random samples by capillary gel electrophoresis (Experion RNA StdSens Analysis Kit, California, USA; Supplementary Table 2 and 3). A noRT PCR control with primers for the eubacterial rrs (16S rRNA subunit) gene (Table 2), was performed for a subset of RNA samples to confirm absence of DNA. The RNA samples were stored at $-80^{\circ} \mathrm{C}$ until Reverse Transcription.

For total DNA extraction, a protocol based on $\mathrm{CTAB} /$ phenol-chloroform lysis with beat-beating and ethanol precipitation (Popova et al., 2010) was followed. The DNA samples were eluted in $30 \mu$ of RNase-free water. Nucleic acid concentrations, 260/280 ratio and 260/230 ratio of all samples were measured using Nanodrop (ND1000 V3.8.1, Wilmington, USA) and the Quantifluor dsDNA system (Promega Benelux, Leiden, The Netherlands). The DNA samples were stored at $-20^{\circ} \mathrm{C}$ until quantitative PCR (qPCR).

\section{Reverse Transcription}

Reverse transcription was performed using the Promega RT system (Promega Benelux) and random hexamer primers $(0.5 \mu \mathrm{g}$, IDT, Leuven, Belgium), starting with ca. $100 \mathrm{ng}$ RNA. Concentrations of cDNA were measured using Nanodrop (ND1000 V3.8.1, Thermo Scientific, Wilmington, USA).

\section{Quantitative PCR}

The qPCR assays were conducted according to the MIQE guidelines (Bustin et al., 2009).

Abundance of total methanogens, eubacteria, and protozoa. The abundance of these microbial groups was quantified using a LightCycler480 Realtime PCR System (Roche Diagnostics, Penzberg, Germany). Target genes were: mor $A$ (methyl coenzyme-M reductase) and methanogenic rrs (16S ribosomal RNA subunit) for methanogens, eubacterial rrs (16S ribosomal RNA subunit) for total eubacteria and protozoal rrs (18S ribosomal RNA subunit) for total protozoa. Samples of a 100-fold dilution of the DNA extracts were used. Amplicon detection was done using SYBR Green technology (SensiFAST SYBR No-ROX kit, Bioline, London, United Kingdom). Reactions were set up in duplo in a white 384 well plate (Bio-Rad Laboratories N.V., Temse, Belgium). Each reaction contained, in a total volume of $10 \mu \mathrm{L}, 5 \mu \mathrm{L}$ SensiFAST SYBR (Bioline), $0.3 \mu \mathrm{L}$ of each primer $(10 \mu \mathrm{M}), 2.4 \mu \mathrm{L}$ of water, and $2 \mu \mathrm{L}$ of DNA. The primers, annealing temperatures, and PCR efficiencies are listed in Table 2. Amplification protocols for total methanogens and eubacteria started with a temperature of $95^{\circ} \mathrm{C}$ for $2 \mathrm{~min}$, followed by 45 cycles of $95^{\circ} \mathrm{C}$ for $5 \mathrm{~s}, 60^{\circ} \mathrm{C}$ for $10 \mathrm{~s}$, and $72^{\circ} \mathrm{C}$ for $20 \mathrm{~s}$. At the end, melting curve analysis was performed as follows: $95^{\circ} \mathrm{C}$ for $5 \mathrm{~s}, 65^{\circ} \mathrm{C}$ for $1 \mathrm{~min}$, and heating to $97^{\circ} \mathrm{C}$ with a ramp rate of $0.06^{\circ} \mathrm{C} / \mathrm{s}$. Data acquisition occurred 10 times for every ${ }^{\circ} \mathrm{C}$. For total protozoa quantification, the same protocol was used, but annealing temperature was set to $57^{\circ} \mathrm{C}$. Within each run, a standard curve was constructed

Table 2. Primers used in this study

\begin{tabular}{|c|c|c|c|c|c|}
\hline Primer pair & Target & Sequence ${ }^{\prime} 5 \rightarrow$ ' 3 & Annealing $\mathrm{T}\left({ }^{\circ} \mathrm{C}\right)$ & $\begin{array}{l}\text { PCR efficiencies } \\
\text { DNA|cDNA }\end{array}$ & Reference \\
\hline qmerA F/qmerA R & $\begin{array}{l}\text { mcr } A \text { total } \\
\text { methanogens }\end{array}$ & $\begin{array}{l}\text { TTC GGT GGA TCD CAR AGR } \\
\text { GC GBA RGT CGW AWC CGT } \\
\text { AGA ATC C }\end{array}$ & 60 & $83 \% \mid 83 \%$ & $\underset{2007}{\text { Denman }}$ et al. \\
\hline Met630 F/Met803 R & $\begin{array}{r}16 S r R N A \text { total } \\
\text { methanogens }\end{array}$ & $\begin{array}{l}\text { GGA TTA GAT ACC CSG GTA } \\
\text { GT GTT GAR TCC AAT TAA } \\
\text { ACC GCA }\end{array}$ & 60 & $81 \% \mid 78 \%$ & Hook et al., 2009 \\
\hline Bac338 F/Bac518 R & $\begin{array}{l}16 S r R N A \text { total } \\
\text { eubacteria }\end{array}$ & $\begin{array}{l}\text { ACT CCT ACG GGA GGC AGC } \\
\text { AG ATT ACC GCG GCT GCT } \\
\text { GG }\end{array}$ & 60 & $82 \%$ & Ovreås et al., 1997 \\
\hline Syl316 F/Syl539 R & $\begin{array}{l}18 S r R N A \text { total } \\
\text { protozoa }\end{array}$ & $\begin{array}{l}\text { GCT TTC GWT GGT AGT GTA } \\
\text { TT CTT GCC CTC YAA TCG } \\
\text { TWC T }\end{array}$ & 57 & $74 \%$ & $\begin{array}{l}\text { Sylvester et al., } \\
\quad 2004\end{array}$ \\
\hline
\end{tabular}


using a 10-fold dilution series of specific gBlock DNA (IDT; Supplementary Table 1), containing a strain-specific sequence for each primer, in order to determine the PCR efficiency (Table 2). The number of gene copies was calculated by converting the quantification cycle values $(\mathrm{Cq})$ to gene copy abundances, taking into account the PCR efficiency as determined by the standard curve. If $\mathrm{Cq}>36$, this was considered as no amplification. Data were analyzed using the LightCycler480 software version 1.5.1.62 (Roche). The results are presented as $\left(\log _{10}\right)$ number of gene copies/ $\mu \mathrm{L}$ DNA extract (eubacteria and protozoa), or number of target gene copies relative to total number of eubacterial rrs copies (for $m c r A$ and methanogenic $r r s$ ).

Activity of methanogens (mcrA gene expression). The same general qPCR protocol specifications and primers (Table 2) were used for the methanogenic activity measurements as for measurement of total methanogen abundance. The abundance of $m c r A$ and methanogenic rrs transcripts (cDNA, 5-fold diluted) from methanogens in all samples was quantified using LightCycler480 software (Roche, Vilvoorde, Belgium). Corresponding noRT samples were included within each run. The $\mathrm{Cq}$ values of noRTs differed at least in five cycles from the samples. Subsequent RNA expression analysis was performed using the program qBase+ (Biogazelle, Zwijnaarde, Belgium; Hellemans et al., 2007). Expression levels of $m c r A$ were normalized using $r r s$ as an internal reference gene and calculated using the mathematical model of Pfaffl (Pfaffl 2001) with gene specific amplification efficiencies, as calculated by the LightCycler480 software (Table 2).

\section{Statistical Analysis}

All goats within one experimental condition were regarded as statistical replicates. Results in tables are shown as least square mean averages. In the case of log-transformed parameters, back-transformed LS means are presented together with the 95\% confidence intervals. Duplicate flasks in the in vitro incubations as well as the 10 papillae measured from one area (per kid) were considered analytical repeats, and mean values of these measurements were used for statistical analysis. Analysis of qPCR data was performed on log-transformed values. Descriptive statistics (mean and SE) were used to create graphs. Values were analyzed by the MIXED procedure in SAS Enterprise (SAS Inst. Inc., Cary, USA) with prenatal treatment, postnatal treatment and the interaction as fixed main factors, and mother identity (kids coming from the same doe) and sampling day as random factors. If data was not normally distributed, then it was log transformed for statistical analyses (i.e. in vitro $\mathrm{H}_{2}$ accumulation and propionate production). When the test showed significant differences, Tukey's post hoc tests were carried out. Statistical significance was assigned to $P<0.05$. Statistical tendency was assigned to $0.05<$ $P<0.10$. When interaction effects were not significant, they were removed from the final model and only the main effects were presented.

\section{RESULTS}

\section{BW and Daily Weight Gain}

Kids' weight upon arrival at the experimental stables (day 2 after birth) was not affected by prenatal treatment of does (Table 3), whereas postnatal supplementation with CO MCFA had a negative impact on total milk replacer intake $(P<0.0001)$ (Figure 3A), particularly in the first 4 wk of age. At the age of $1 \mathrm{wk}$, postnatally treated kids $(\mathrm{K}+)$ consumed $25 \%$ less milk replacer compared to $\mathrm{K}$ - kids, but the difference was largest in weeks 2 and 3, when $\mathrm{K}+$ kids consumed $32 \%$ and $31 \%$ less milk replacer than $\mathrm{K}-$ kids, respectively (Figure 3B). After week 4 of life, the differences in milk replacer intake were declining. In the week prior to weaning, all kids consumed the same amount of milk replacer. Mean total concentrate intake until 13 wk of $\mathrm{D}-\mathrm{K}+$ kids was largely influenced by intake of two kids (same pen). Without these two kids total concentrate intake was $18.6 \mathrm{~kg} \mathrm{DM} /$ pen (compared to $15.0 \mathrm{~kg}$ $\mathrm{DM} /$ pen, as presented in Figure 3A). However, total concentrate intake was not different between experimental groups whether or not this pen was excluded from the analysis. The lower milk replacer intake of $\mathrm{K}+$ kids during the first weeks resulted in a reduced daily weight gain and BW during the first $4 \mathrm{wks}$ of life (Table 3). The $\mathrm{K}+$ kids retained a lower BW compared to $\mathrm{K}$ - kids during the entire postnatal treatment period (birth until $11 \mathrm{wk}$ ) and beyond: until end of the indoor stable period (13 wk, $P=0.009)$ and at euthanasia ( $28 \mathrm{wk}, P=0.09$ ). Overall, average daily weight gain from day 2 after birth until weaning remained lowest in $\mathrm{K}+$ kids $(P=0.001)$. After the indoor period (wk 13), D+ kids tended to have an increased daily weight gain $(P=0.07)$. Although concentrate intake during the indoor stable period of two kids of the $\mathrm{D}-\mathrm{K}+$ group was extremely low compared to the other 8 kids in the group $(0.757 \mathrm{~kg} /$ pen vs. $21.2 \mathrm{~kg} /$ pen group average), $\mathrm{BW}$ of these animals did not deviate from the group 
Table 3. Effect of prenatal or postnatal treatment with MCFA from coconut oil on BW and daily weight gain of goat kids

\begin{tabular}{|c|c|c|c|c|c|c|c|}
\hline \multirow[b]{2}{*}{ Item } & \multicolumn{4}{|c|}{ Treatments* } & \multirow[b]{2}{*}{ SEM } & \multicolumn{2}{|c|}{$P$ value } \\
\hline & $\mathrm{D}+$ & $\mathrm{D}-$ & $\mathrm{K}+$ & $\mathrm{K}-$ & & Prenatal treatment & Postnatal treatment \\
\hline \multicolumn{8}{|l|}{$\overline{\mathrm{BW}}, \mathrm{kg}$} \\
\hline Day 2 & 3.96 & 3.76 & 3.89 & 3.82 & 0.132 & 0.33 & 0.64 \\
\hline Wk 2 & 5.53 & 5.55 & 5.00 & 6.07 & 0.184 & 0.94 & 0.0003 \\
\hline Wk 4 & 8.11 & 8.28 & 7.32 & 9.07 & 0.302 & 0.70 & 0.0007 \\
\hline Wk 6 & 11.5 & 11.3 & 10.5 & 12.3 & 0.38 & 0.82 & 0.002 \\
\hline Wk 8 & 14.3 & 14.6 & 13.3 & 15.5 & 0.46 & 0.70 & 0.004 \\
\hline Wk 9 (weaning) & 16.4 & 16.4 & 15.3 & 17.6 & 0.51 & 0.99 & 0.004 \\
\hline Wk 13 & 23.2 & 22.3 & 21.3 & 24.2 & 0.67 & 0.39 & 0.009 \\
\hline Euthanasia (ca. $28 \mathrm{wk}$ ) & 32.6 & 30.7 & 30.5 & 32.8 & 0.92 & 0.16 & 0.092 \\
\hline \multicolumn{8}{|l|}{ Daily weight gain, g/d } \\
\hline $0-2$ wk & 102 & 116 & 71.4 & 146 & 8.1 & 0.22 & $<0.0001$ \\
\hline $2-4 \mathrm{wk}$ & 186 & 195 & 166 & 215 & 13.0 & 0.61 & 0.02 \\
\hline $4-6 \mathrm{wk}$ & 240 & 219 & 225 & 234 & 14.0 & 0.32 & 0.68 \\
\hline $6-8 \mathrm{wk}$ & 203 & 229 & 204 & 227 & 13.7 & 0.19 & 0.26 \\
\hline 0 -weaning & 196 & 196 & 177 & 216 & 7.1 & 0.98 & 0.001 \\
\hline Weaning-13 wk & 249 & 218 & 227 & 241 & 11.1 & 0.07 & 0.35 \\
\hline 13 wk-euth. (pasture) & 86.4 & 75.2 & 83.0 & 78.6 & 5.33 & 0.16 & 0.54 \\
\hline ADG trial (0-euth.) & 143 & 133 & 132 & 144 & 4.1 & 0.09 & 0.05 \\
\hline
\end{tabular}

*Treatments consisted of four combinations of pre (D+ or D-) and/or postnatal $(\mathrm{K}+$ or $\mathrm{K}-$ ) treatment. Since interaction effects between $\mathrm{D}$ and $\mathrm{K}$ were not significant, only main effects are presented. Number of kids per treatment: $\mathrm{D}+\mathrm{K}+(n=10), \mathrm{D}+\mathrm{K}-(n=9), \mathrm{D}-\mathrm{K}+(n=10)$, $\mathrm{D}-\mathrm{K}-(n=10)$.

mean. Daily weight gain over the whole pasture period (13-28 wk) did not differ between treatment groups. Over the whole trial, $\mathrm{K}+$ kids had the lowest average daily weight gain (Table $3, P=0.05$ ).

\section{In Vitro Rumen Fermentation}

Four wk old (4 and $24 \mathrm{~h}$ incubation). At $4 \mathrm{wk}$ old, absolute $\mathrm{CH}_{4}$ production after 4-h incubation was lower in rumen inoculum of $\mathrm{D}+$ kids $(-48 \%$,
$P=0.003)$ and of $\mathrm{K}+$ kids $(-43 \%, P=0.01)$, compared with kids which did not receive any treatment prenatally or postnatally (Table 4). Associated to this $\mathrm{CH}_{4}$ reduction, total VFA (tVFA) was lower in $\mathrm{D}+$ kids and this decrease tended to be stronger for kids that also received a postnatal treatment (interaction, $P=0.06$ ). These $\mathrm{D}+\mathrm{K}+$ kids also had the lowest acetate/propionate ratio $(P=0.04)$ and butyrate production $(P=0.03)$. Propionate production was increased in $\mathrm{K}+$ kids $(+40 \%, P=0.01)$;
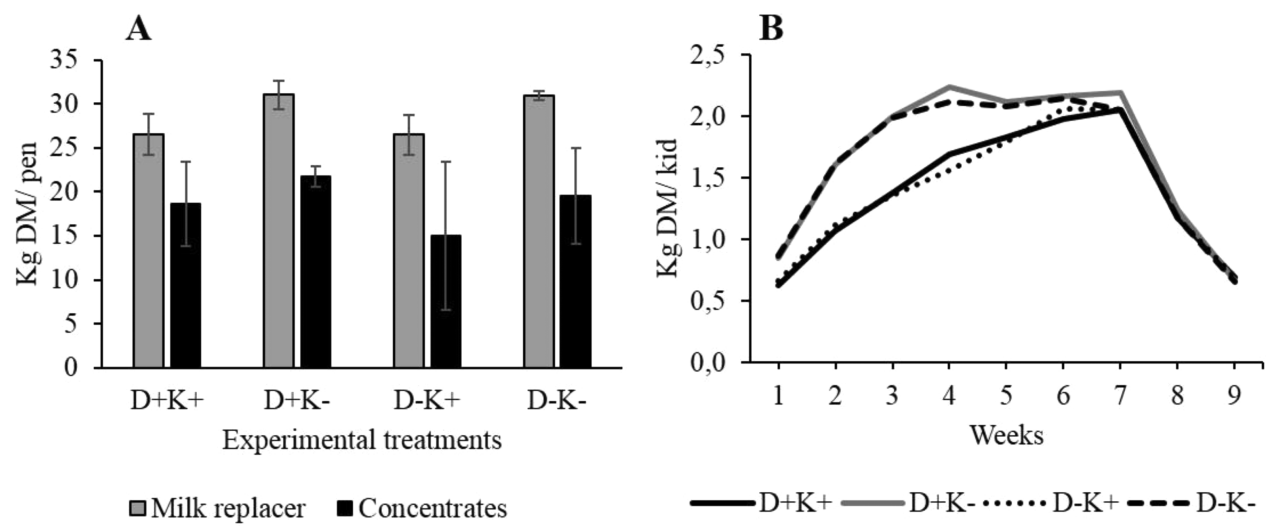

Figure 3. (A) Total milk replacer and concentrate intake ( $\mathrm{kg} \mathrm{DM} / \mathrm{pen})$ during the entire indoor stable period ( $0-13$ wk). Values represent mean intake per pen and error bars represent SDs $(n=5)$. Total milk replacer intake of postnatally treated kids $(\mathrm{K}+)$ was reduced compared to the $\mathrm{K}-$ group $(P=0.004)$. Total concentrate intake of $\mathrm{D}-\mathrm{K}+$ kids was largely influenced by intake of two kids (same pen). Without these two goats total concentrate intake was $18.6 \mathrm{~kg}$ DM (compared to $15.0 \mathrm{~kg} \mathrm{DM}$, as presented in the figure). However, total concentrate intake was not different between experimental groups whether or not this pen was excluded from the analysis. (B) Mean milk replacer intake per week (kg DM/kid) during the preweaning period. Data were calculated as total intake per week for each experimental treatment group divided by the number of kids within that group. 
Table 4. In vitro fermentation parameters of rumen fluid of goat kids, 4 wks old ( 4 and $24 \mathrm{~h}$ incubation)

\begin{tabular}{|c|c|c|c|c|c|c|c|c|}
\hline \multicolumn{6}{|c|}{ Treatments* } & \multicolumn{3}{|c|}{$P$ value } \\
\hline Item & $\mathrm{D}+\mathrm{K}+(n=10)$ & $\mathrm{D}+\mathrm{K}-(n=9)$ & $\mathrm{D}-\mathrm{K}+(n=10)$ & $\mathrm{D}-\mathrm{K}-(n=10)$ & SEM & Prenatal treatment & Postnatal treatment & Interaction \\
\hline \multicolumn{9}{|c|}{ Absolute $\mathrm{CH}_{4}$ production, $\mu \mathrm{mol} /$ flask } \\
\hline $4 \mathrm{~h}$ & 6.78 & 26.6 & 28.7 & 35.8 & 3.33 & 0.003 & 0.01 & $\mathrm{NS}^{\dagger}$ \\
\hline $24 \mathrm{~h}$ & $23.5^{\mathrm{b}}$ & $127^{\mathrm{a}}$ & $103^{\mathrm{a}}$ & $133^{\mathrm{a}}$ & 12.9 & 0.004 & $<0.0001$ & 0.01 \\
\hline \multicolumn{9}{|c|}{ Absolute $\mathrm{H}_{2}$ accumulation ${ }^{\ddagger}, \mu \mathrm{mol} /$ flask } \\
\hline $4 \mathrm{~h}$ & 13.1 & 7.29 & 10.9 & 5.73 & & 0.51 & 0.07 & NS \\
\hline $24 \mathrm{~h}$ & $32.3^{\mathrm{a}}$ & $2.27^{\mathrm{b}}$ & $2.51^{\mathrm{b}}$ & $1.32^{\mathrm{b}}$ & & 0.0009 & 0.0001 & 0.008 \\
\hline \multicolumn{9}{|c|}{ Relative $\mathrm{CH}_{4}$ production $\left(\mathrm{CH}_{4} /\right.$ total VFA, $\left.\mu \mathrm{mol} / \mu \mathrm{mol}\right)$} \\
\hline $4 \mathrm{~h}$ & 0.0435 & 0.193 & 0.156 & 0.232 & 0.0200 & 0.02 & 0.001 & NS \\
\hline $24 \mathrm{~h}$ & $0.0648^{\mathrm{b}}$ & $0.307^{\mathrm{a}}$ & $0.263^{\mathrm{a}}$ & $0.349^{\mathrm{a}}$ & 0.0309 & 0.001 & $<0.0001$ & 0.02 \\
\hline \multicolumn{9}{|c|}{ VFA production, $\mu \mathrm{mol} /$ flask } \\
\hline \multicolumn{9}{|c|}{ Total VFA } \\
\hline $4 \mathrm{~h}$ & 113 & 153 & 181 & 154 & 16.5 & 0.05 & 0.71 & 0.06 \\
\hline $24 \mathrm{~h}$ & $285^{\mathrm{b}}$ & $415^{\mathrm{a}}$ & $388^{\mathrm{a}}$ & $378^{\mathrm{a}}$ & 22.1 & 0.15 & 0.02 & 0.006 \\
\hline \multicolumn{9}{|c|}{ Acetate } \\
\hline $4 \mathrm{~h}$ & 48.0 & 62.1 & 71.2 & 60.3 & 7.38 & 0.31 & 0.97 & NS \\
\hline $24 \mathrm{~h}$ & $137^{\mathrm{b}}$ & $215^{\mathrm{a}}$ & $201^{\mathrm{a}}$ & $207^{a}$ & 16.5 & 0.11 & 0.02 & 0.05 \\
\hline \multicolumn{9}{|c|}{ Propionate $^{\dagger}$} \\
\hline $4 \mathrm{~h}$ & 36.5 & 25.6 & 36.6 & 26.6 & & 0.87 & 0.01 & NS \\
\hline $24 \mathrm{~h}$ & 93.9 & 74.3 & 71.6 & 59.1 & & 0.03 & 0.07 & NS \\
\hline \multicolumn{9}{|c|}{ Butyrate } \\
\hline $4 \mathrm{~h}$ & $20.8^{\mathrm{b}}$ & $50.9^{\mathrm{a}}$ & $52.3^{\mathrm{a}}$ & $50.9^{\mathrm{a}}$ & 6.65 & 0.29 & 0.05 & 0.03 \\
\hline $24 \mathrm{~h}$ & $48.9^{\mathrm{b}}$ & $99.3^{\mathrm{a}}$ & $81.8^{\mathrm{a}}$ & $85.0^{\mathrm{a}}$ & 7.28 & 0.27 & 0.001 & 0.003 \\
\hline \multicolumn{9}{|c|}{ Acetate/propionate ratio } \\
\hline $4 \mathrm{~h}$ & $1.16^{\mathrm{b}}$ & $2.47^{\mathrm{a}}$ & $2.07^{\mathrm{a}}$ & $2.11^{\mathrm{a}}$ & 0.322 & 0.44 & 0.04 & 0.04 \\
\hline $24 \mathrm{~h}$ & 1.46 & 2.89 & 3.02 & 3.80 & 0.279 & 0.006 & 0.01 & NS \\
\hline
\end{tabular}

*Treatments consisted of four combinations of pre $(\mathrm{D}+$ or $\mathrm{D}-)$ and/or postnatal $(\mathrm{K}+$ or $\mathrm{K}-)$ treatment. Main and interaction effects are presented. Means with different superscripts differ $(P<0.05)$. Superscripts are only shown when an interaction effect was detected.

NSS: nonsignificant $P$ values for interaction effects. Interaction effects were omitted from the mixed model when not significant, hence no $P$ value is presented.

${ }^{\ddagger} \log$ transformation was performed for this parameter. Back-transformed LS means are presented. No meaningful SEM can be presented for these parameters, instead confidence intervals $(95 \%)$ per exp. group ([lower limit; upper limit]) are presented in same order as in the table. $\mathrm{H}_{2}(4 \mathrm{~h})$ : [2.95; 11.1], [5.60;21.1], [3.48; 15.3], [6.76; 25.4]; $\mathrm{H}_{2}(24 \mathrm{~h}):$ [0.62; 2.82], [1.17; 5.37], [1.02; 5.03], [15.1; 69.0]; propionate (4 h): [20.7; 34.2], [28.4; 47.1], [19.3; 33.9], [27.9; 47.6], propionate (24 h): [47.1; 74.1], [57.1; 95.3], [58.5; 94.4], [74.0; 119].

${ }^{\S}$ Total VFA consisting of seven short chain fatty acids: C2:0 (acetate), C3:0 (propionate), iso-C4:0 (iso-butyrate), C4:0 (butyrate), iso-C5:0 (iso-valerate), C5:0 (valerate), and C6:0 (caprionate).

however, acetate production was not different $(P>$ $0.05)$ between groups. The production of $\mathrm{CH}_{4}$ relatively to tVFA $\left(\mathrm{CH}_{4} / \mathrm{tVFA}\right)$ was reduced in both $\mathrm{D}+$ kids $(-39 \%, P=0.01)$ and $\mathrm{K}+$ kids $(-53 \%$, $P=0.001)$, and a trend was observed for higher $\mathrm{H}_{2}$ accumulation in flasks with rumen inoculum of $\mathrm{K}+$ kids $(P=0.07)$. Results after 24 -h incubation showed $\mathrm{D}+\mathrm{K}+$ kids' inocula had the lowest in vitro $\mathrm{CH}_{4}$ production $(-82 \%)$ accompanied by a very high $\mathrm{H}_{2}$ accumulation (25-fold higher than D-K- kids) (interaction; $P=0.01$ and $P=0.008$, respectively). The rumen fluid of these kids further presented a decreased tVFA, acetate, and butyrate production (interaction; $P=0.006, P=0.05$, and $P=0.003$, respectively). This resulted in a lower $\mathrm{CH}_{4} /$ tVFA ratio in $\mathrm{D}+\mathrm{K}+$ kids (interaction, $P=0.02$ ). Production of propionate was increased in $\mathrm{D}+$ kids
$(+28 \%, P=0.03)$ and $\mathrm{K}+$ kids $(+24 \%, P=0.07)$, and the acetate/propionate ratio was decreased (D+ kids, $P=0.005 ; \mathrm{K}+$ kids, $P=0.01)$. Nonincubated inocula of the fasted kids were also analyzed to provide insight into the in vivo concentrations of VFA (Supplementary Table 4). At 4 wk of age, no differences in tVFA concentrations or acetate were present in these nonincubated inocula; however, the amount of butyrate was higher in $\mathrm{D}-\mathrm{K}+$ kids compared to $\mathrm{D}-\mathrm{K}-\mathrm{kids}(P=0.02)$ and the amount of propionate was higher in $\mathrm{D}+$ kids $(P=0.04)$, an effect that was also visible after $24 \mathrm{~h}$ incubation.

Eleven wk old (4 and $24 \mathrm{~h}$ incubation). At $11 \mathrm{wk}$, incubation results of two $\mathrm{D}-\mathrm{K}+$ kids largely deviated from the eight other kids in the $\mathrm{D}-\mathrm{K}+$ group with regards to intake (lower concentrate intake and higher hay intake), and were 
highly influencing the results of the $\mathrm{D}-\mathrm{K}+$ group (Table 5). Accordingly, it was decided to leave the two kids out of this analysis $(n=8)$. The treatment effects that were observed at 4 wk old had disappeared at $11 \mathrm{wk}$ old. There were no differences observed in absolute $\mathrm{CH}_{4}$ production, absolute $\mathrm{H}_{2}$ accumulation or $\mathrm{CH}_{4} / \mathrm{tVFA}$ after 4 or $24 \mathrm{~h}$ of incubation. There was a trend for lower tVFA $(P=0.06)$ and a significantly lower production of acetate $(-15 \%, P=0.005)$ in $\mathrm{K}+$ kids after $4 \mathrm{~h}$ incubation. After 24-h incubation, there was no difference anymore in acetate production; however, there was still a trend for lower tVFA in $\mathrm{K}+$ kids $(P=0.10)$ and also for lower acetate/propionate ratio in $\mathrm{D}+$ kids $(P=0.06)$, corresponding to results at $4 \mathrm{wk}$ after $24 \mathrm{~h}$ incubation. The fermentative capacity of $\mathrm{D}+\mathrm{K}+$ kids' inoculum had doubled compared to $4 \mathrm{wk}$ old (reflected in tVFA production after $24 \mathrm{~h}$ incubation), together with a strong increase in absolute $\mathrm{CH}_{4}$ production. For nonincubated rumen fluid samples, the only statistical difference (confirmed as a trend by Tukey's Post Hoc test) was found in acetate concentration, which was higher in $\mathrm{D}-\mathrm{K}+$ inocula compared to $\mathrm{D}+\mathrm{K}+$ inocula (Supplementary Table 4).

Twenty-four wk old (4 and $24 \mathrm{~h}$ incubation). There were no differences in absolute $\mathrm{CH}_{4}$ production, $\mathrm{H}_{2}$ accumulation, tVFA, individual VFAs, or $\mathrm{CH}_{4} / \mathrm{tVFA}$ after 4 or $24 \mathrm{~h}$ incubation, nor for nonincubated samples (Table 6). In general, for inocula from all experimental conditions, tVFA and absolute $\mathrm{CH}_{4}$ production values had doubled compared to results from 11-wk-old animals $(24 \mathrm{~h}$ incubation).

Table 5. In vitro fermentation parameters of rumen fluid of goat kids, 11 weeks old (4 and 24 hours incubation)

\begin{tabular}{|c|c|c|c|c|c|c|c|}
\hline \multicolumn{6}{|c|}{ Treatments* } & \multicolumn{2}{|c|}{$P$ value } \\
\hline Item & $\mathrm{D}+$ & D- & $\mathrm{K}+$ & $\mathrm{K}-$ & SEM & Prenatal treatment & Postnatal treatment \\
\hline \multicolumn{8}{|c|}{ Absolute $\mathrm{CH}_{4}$ production, $\mu \mathrm{mol} /$ flask } \\
\hline $4 \mathrm{~h}$ & 37.3 & 42.8 & 40.1 & 40.0 & 4.37 & 0.42 & 0.99 \\
\hline $24 \mathrm{~h}$ & 140 & 148 & 149 & 139 & 9.2 & 0.54 & 0.35 \\
\hline \multicolumn{8}{|c|}{ Absolute $\mathrm{H}_{2}$ accumulation ${ }^{\dagger}, \mu \mathrm{mol} /$ flask } \\
\hline $4 \mathrm{~h}$ & 2.65 & 3.20 & 2.15 & 3.70 & & 0.56 & 0.42 \\
\hline $24 \mathrm{~h}$ & 1.08 & 0.92 & 1.07 & 0.93 & & 0.63 & 0.29 \\
\hline \multicolumn{8}{|c|}{ Relative $\mathrm{CH}_{4}$ production $\left(\mathrm{CH}_{4} /\right.$ total VFA, $\left.\mu \mathrm{mol} / \mu \mathrm{mol}\right)$} \\
\hline $4 \mathrm{~h}$ & 0.160 & 0.171 & 0.174 & 0.157 & 0.0178 & 0.67 & 0.46 \\
\hline $24 \mathrm{~h}$ & 0.266 & 0.276 & 0.287 & 0.255 & 0.0164 & 0.66 & 0.13 \\
\hline \multicolumn{8}{|c|}{ VFA production, $\mu \mathrm{mol} / \mathrm{flask}$} \\
\hline \multicolumn{8}{|c|}{ Total VFA } \\
\hline $4 \mathrm{~h}$ & 237 & 250 & 234 & 254 & 7.8 & 0.26 & 0.06 \\
\hline $24 \mathrm{~h}$ & 527 & 538 & 518 & 547 & 12.8 & 0.55 & 0.10 \\
\hline \multicolumn{8}{|c|}{ Acetate } \\
\hline $4 \mathrm{~h}$ & 115 & 126 & 111 & 130 & 5.3 & 0.19 & 0.005 \\
\hline $24 \mathrm{~h}$ & 305 & 325 & 307 & 323 & 9.0 & 0.16 & 0.13 \\
\hline \multicolumn{8}{|c|}{ Propionate $^{\dagger}$} \\
\hline $4 \mathrm{~h}$ & 83.0 & 79.3 & 79.4 & 82.9 & & 0.85 & 0.44 \\
\hline $24 \mathrm{~h}$ & 149 & 137 & 134 & 152 & & 0.25 & 0.16 \\
\hline \multicolumn{8}{|c|}{ Butyrate } \\
\hline $4 \mathrm{~h}$ & 24.4 & 26.4 & 25.6 & 25.2 & 2.42 & 0.57 & 0.90 \\
\hline $24 \mathrm{~h}$ & 45.7 & 44.7 & 45.1 & 45.2 & 3.29 & 0.84 & 0.98 \\
\hline \multicolumn{8}{|c|}{ Acetate/propionate ratio } \\
\hline $4 \mathrm{~h}$ & 1.50 & 1.64 & 1.51 & 1.62 & 0.095 & 0.31 & 0.40 \\
\hline $24 \mathrm{~h}$ & 2.10 & 2.54 & 2.42 & 2.22 & 0.150 & 0.06 & 0.30 \\
\hline
\end{tabular}

*Treatments consisted of four combinations of pre ( $\mathrm{D}+$ or $\mathrm{D}-)$ and/or postnatal $(\mathrm{K}+$ or $\mathrm{K}-)$ treatment. Since interaction effects between $\mathrm{D}$ and $\mathrm{K}$ were not significant, only main effects are presented. Number of kids per treatment: $\mathrm{D}+\mathrm{K}+(n=10), \mathrm{D}+\mathrm{K}-(n=9), \mathrm{D}-\mathrm{K}+(n=8)$, and $\mathrm{D}-\mathrm{K}-(n=10)$.

${ }^{\dagger} \log$ transformation was performed for this parameter. Back-transformed LS means are presented. No meaningful SEM can be presented for these parameters, instead confidence intervals $(95 \%)$ per exp. group ([lower limit; upper limit]) are presented in same order as in the table. $\mathrm{H}_{2}(4 \mathrm{~h})$ : [1.44; 6.21], [1.60; 3.31], [1.35; 2.80], [1.67; 3.37], $\mathrm{H}_{2}(24 \mathrm{~h}):$ [0.67; 1.28], [0.59; 1.13], [0.71; 1.22], [0.62; 1.05], Propionate (4 h): [68.0; 91.5], [65.8; 90.8], [64.1; 88.0], [69.7; 94.6], Propionate (24 h): [130; 165], [117; 151], [116; 149], [131; 167].

tTotal VFA consisting of seven short chain fatty acids: C2:0 (acetate), C3:0 (propionate), iso-C4:0 (iso-butyrate), C4:0 (butyrate), iso-C5:0 (iso-valerate), C5:0 (valerate), and C6:0 (caprionate). 


\section{Rumen Microbiota}

Total DNA yield increased with age of kids $(P<0.0001)$. The lowest DNA yield was observed in $\mathrm{D}+\mathrm{K}+$ kids at $4 \mathrm{wk}$ old $(P=0.05$; Table 7$)$. In addition, total eubacterial abundance was lowest in these kids at $4 \mathrm{wk}(P=0.02$, Table 7$)$, as was total methanogen abundance (measured both as rrs or $m c r A$ abundance relatively to eubacterial rrs abundance, $P=0.01$ and $P=0.002$, respectively; Figure 4). At 11 and 28 wk old, differences in eubacterial and methanogen abundance disappeared. The qPCR-based tests for total protozoal abundance revealed virtually no protozoa were present in the rumen fluid of kids up until $28 \mathrm{wk}$ of age, irrespective of experimental treatment. Methanogenic activity ( $m$ cr $A$ transcripts normalized against methanogen $r r s$ transcripts), after a night of fasting was numerically lowest in $\mathrm{D}+\mathrm{K}+$ kids at $4 \mathrm{wk}$ old, but this was not different from expression levels in $\mathrm{D}+\mathrm{K}-$ or $\mathrm{D}-$ $\mathrm{K}-$ kids (Figure 5). However, taking into account the lower total methanogen abundance in $\mathrm{D}+\mathrm{K}+$ kids at 4 wk old, overall rumen methanogenic activity will be strongly reduced in these kids. Expression levels in $\mathrm{D}-\mathrm{K}+$ kids were higher than in $\mathrm{D}+\mathrm{K}+$ kids at this age (interaction, $P=0.004$ ). At 11 wk old, there were no differences in $m c r A$ expression detected, however at 28 wk old an interaction effect was detected $(P=0.005)$, showing highest levels of expression in rumen fluid of singularly treated kids ( $\mathrm{D}+\mathrm{K}-$ and $\mathrm{D}-\mathrm{K}+$ kids).

Table 6. In vitro fermentation parameters of rumen fluid of goat kids, 28 weeks old ( 4 and 24 hours incubation)

\begin{tabular}{|c|c|c|c|c|c|c|c|}
\hline \multirow[b]{2}{*}{ Item } & \multicolumn{4}{|c|}{ Treatments* } & \multirow[b]{2}{*}{ SEM } & \multicolumn{2}{|c|}{$P$ value } \\
\hline & $\mathrm{D}+$ & D- & $\mathrm{K}+$ & $\mathrm{K}^{-}$ & & Prenatal treatment & Postnatal treatment \\
\hline \multicolumn{8}{|c|}{ Absolute $\mathrm{CH}_{4}$ production, $\mu \mathrm{mol} /$ flask } \\
\hline $4 \mathrm{~h}$ & 98.5 & 98.0 & 99.0 & 97.5 & 4.45 & 0.93 & 0.82 \\
\hline $24 \mathrm{~h}$ & 341 & 347 & 349 & 339 & 15.0 & 0.80 & 0.56 \\
\hline \multicolumn{8}{|c|}{ Absolute $\mathrm{H}_{2}$ accumulation ${ }^{\dagger}, \mu \mathrm{mol} / \mathrm{flask}$} \\
\hline $4 \mathrm{~h}$ & 1.83 & 1.56 & 1.79 & 1.61 & & 0.28 & 0.46 \\
\hline $24 \mathrm{~h}$ & 0.533 & 0.560 & 0.559 & 0.533 & & 0.47 & 0.49 \\
\hline \multicolumn{8}{|c|}{ Relative $\mathrm{CH}_{4}$ production $\left(\mathrm{CH}_{4} /\right.$ total VFA, $\left.\mu \mathrm{mol} / \mu \mathrm{mol}\right)$} \\
\hline $4 \mathrm{~h}$ & 0.257 & 0.265 & 0.264 & 0.259 & 0.0129 & 0.66 & 0.79 \\
\hline $24 \mathrm{~h}$ & 0.313 & 0.334 & 0.328 & 0.319 & 0.0143 & 0.31 & 0.68 \\
\hline \multicolumn{8}{|c|}{ VFA production, $\mu \mathrm{mol} / \mathrm{flask}$} \\
\hline \multicolumn{8}{|c|}{ Total VFA } \\
\hline $4 \mathrm{~h}$ & 386 & 375 & 380 & 381 & 14.0 & 0.62 & 0.94 \\
\hline $24 \mathrm{~h}$ & 1,085 & 1,077 & 1,093 & 1,069 & 21.6 & 0.80 & 0.45 \\
\hline \multicolumn{8}{|l|}{ Acetate } \\
\hline $4 \mathrm{~h}$ & 189 & 176 & 178 & 186 & 7.2 & 0.20 & 0.47 \\
\hline $24 \mathrm{~h}$ & 631 & 616 & 634 & 612 & 17.7 & 0.57 & 0.33 \\
\hline \multicolumn{8}{|c|}{ Propionate $^{\dagger}$} \\
\hline $4 \mathrm{~h}$ & 115 & 119 & 118 & 117 & & 0.80 & 0.99 \\
\hline $24 \mathrm{~h}$ & 308 & 304 & 309 & 304 & & 0.69 & 0.67 \\
\hline \multicolumn{8}{|c|}{ Butyrate } \\
\hline $4 \mathrm{~h}$ & 54.4 & 54.0 & 56.0 & 52.4 & 4.70 & 0.87 & 0.50 \\
\hline $24 \mathrm{~h}$ & 100 & 99.3 & 100 & 99.5 & 4.86 & 0.88 & 0.93 \\
\hline \multicolumn{8}{|c|}{ Acetate/propionate ratio } \\
\hline $4 \mathrm{~h}$ & 1.72 & 1.54 & 1.60 & 1.66 & 0.117 & 0.21 & 0.83 \\
\hline $24 \mathrm{~h}$ & 2.04 & 2.05 & 2.05 & 2.04 & 0.085 & 0.95 & 0.96 \\
\hline
\end{tabular}

*Treatments consisted of four combinations of pre (D+ or D-) and/or postnatal $(\mathrm{K}+$ or $\mathrm{K}-$ treatment. Since interaction effects between $\mathrm{D}$ and $\mathrm{K}$ were not significant, only main effects are presented. Number of kids per treatment: $\mathrm{D}+\mathrm{K}+(n=9), \mathrm{D}+\mathrm{K}-(n=7), \mathrm{D}-\mathrm{K}+(n=7), \mathrm{D}-\mathrm{K}-(n=7)$.

${ }^{\dagger} \log$ transformation was performed for this parameter. Back-transformed LS means are presented. No meaningful SEM can be presented for these parameters, instead confidence intervals $(95 \%)$ per exp. group ([lower limit; upper limit]) are presented in same order as in the table. $\mathrm{H}_{2}(4 \mathrm{~h})$ : [1.47; 2.03], [1.28; 1.81], [1.43; 1.99], [1.31; 1.85], $\mathrm{H}_{2}(24 \mathrm{~h})$ : [0.47; 0.58], [0.49; 0.62], [0.49; 0.61], [0.46; 0.59], Propionate (4 h): [97.9; 129], [100; 134], [98.9; 132], [97.9; 133], Propionate (24 h): [286; 330], [279; 325], [285; 332], [277; 326].

Total VFA consisting of 7 short chain fatty acids: C2:0 (acetate), C3:0 (propionate), iso-C4:0 (iso-butyrate), C4:0 (butyrate), iso-C5:0 (iso-valerate), C5:0 (valerate), and C6:0 (caprionate). 
Table 7. Abundance of total eubacteria (estimated by quantitative PCR) and DNA yield (estimated fluorometrically)

\begin{tabular}{|c|c|c|c|c|c|c|c|c|}
\hline \multicolumn{6}{|c|}{ Treatments* } & \multicolumn{3}{|c|}{$P$ value } \\
\hline Item & $\begin{array}{l}\mathrm{D}+\mathrm{K}+ \\
(n=10)\end{array}$ & $\begin{array}{l}\mathrm{D}+\mathrm{K}- \\
(n=9)\end{array}$ & $\begin{array}{l}\mathrm{D}-\mathrm{K}+ \\
(n=10)\end{array}$ & $\begin{array}{l}\mathrm{D}-\mathrm{K}- \\
(n=10)\end{array}$ & SEM & Prenatal treatment & Postnatal treatment & Interaction \\
\hline \multicolumn{9}{|c|}{$\overline{\text { DNA yield, } n g / \mu L \text { DNA extract }}$} \\
\hline 4 wk & $13.6^{\mathrm{b}}$ & $42.9^{\mathrm{ab}}$ & $62.8^{\mathrm{a}}$ & $47.3^{\mathrm{ab}}$ & 10.75 & 0.02 & 0.53 & 0.05 \\
\hline $11 \mathrm{wk}$ & 73.2 & 83.9 & 81.3 & 73.5 & 10.73 & 0.91 & 0.46 & NS \\
\hline $28 \mathrm{wk}$ & 85.1 & 111 & 114 & 124 & 22.55 & 0.34 & 0.42 & NS \\
\hline \multicolumn{9}{|c|}{ Total eubacteria, $\log _{10}$ gene copies of $r r s / \mu \mathrm{L}$ DNA extract } \\
\hline 4 wk & $5.75^{\mathrm{b}}$ & $6.30^{\mathrm{a}}$ & $6.46^{\mathrm{a}}$ & $6.31^{\mathrm{a}}$ & 0.133 & 0.02 & 0.16 & 0.02 \\
\hline $11 \mathrm{wk}$ & 6.76 & 6.77 & 6.83 & 6.78 & 0.056 & 0.52 & 0.58 & NS \\
\hline $28 \mathrm{wk}$ & 6.67 & 6.80 & 6.82 & 6.85 & 0.093 & 0.28 & 0.38 & NS \\
\hline
\end{tabular}

*Treatments consisted of four combinations of pre ( $\mathrm{D}+$ or $\mathrm{D}-)$ and/or postnatal $(\mathrm{K}+$ or $\mathrm{K}-)$ treatment. Main and interaction effects are presented. Means with different superscripts differ $(P<0.05)$. Superscripts are only shown when an interaction effect was detected.

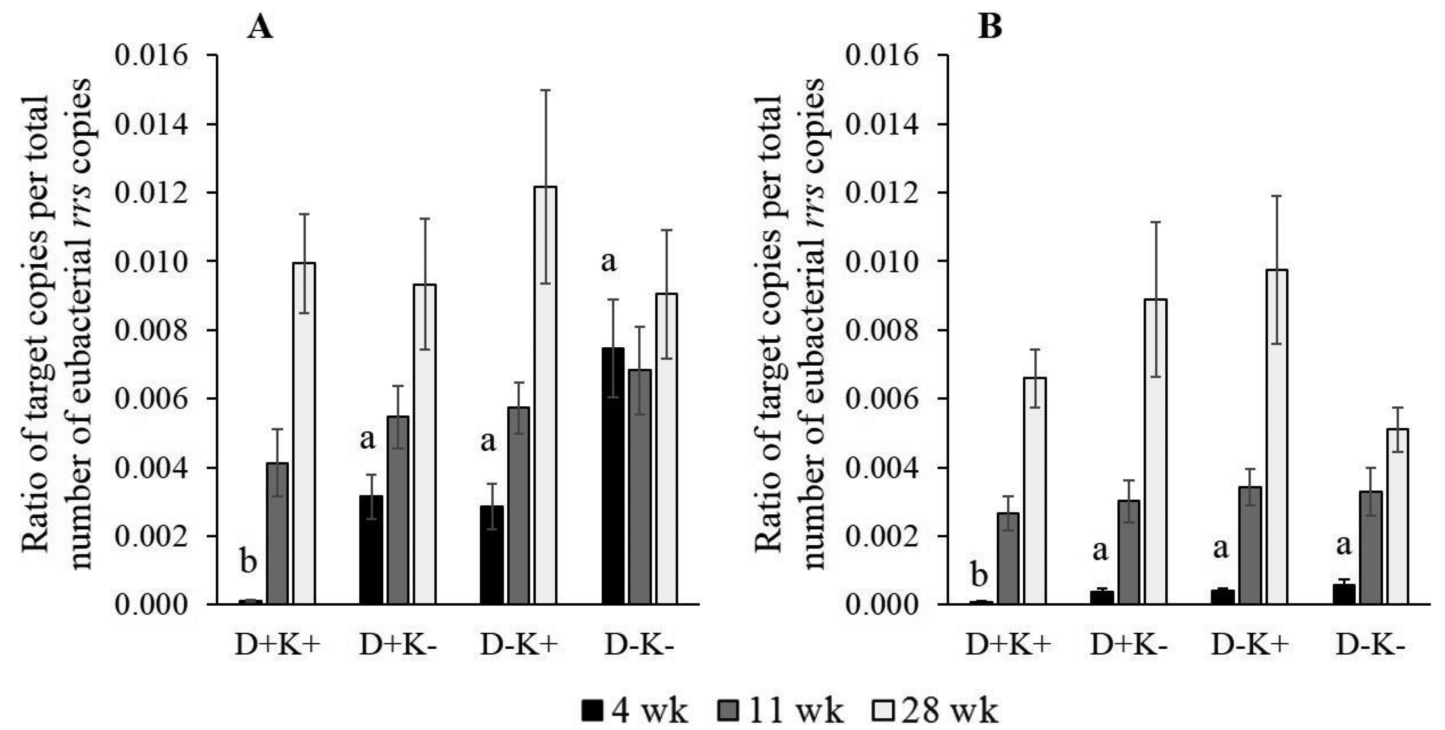

Figure 4. Relative abundance of rumen methanogens. Mean values per experimental group are presented and error bars represent SEs. Means with different letters differ $(P<0.05)$. (A) abundance of $r r s$ of methanogens relatively to abundance of $r r s$ of eubacteria; (B) abundance of $m c r A$ relatively to abundance of $r r s$ of eubacteria.

\section{Rumen Characteristics and Morphometric Properties of Ruminal Papillae}

The empty rumen weight of $\mathrm{K}+$ kids was lower $(P=0.05)$ compared to $\mathrm{K}-$ kids (Table 8$)$. Empty rumen weight expressed as a percentage of total BW was not different between kids, which suggests the lower empty rumen weight was probably caused by the general lower BW. The density of the papillae (number $/ \mathrm{cm}^{2}$ mucosa), observed by stereomicroscope in four different areas of the rumen, did not differ $(P$ $>0.05$ ) between the experimental groups for the ventral rumen, ventral blind sac, and dorsal blind sac. However, papillae density was greater in the ruminal atrium of $\mathrm{K}+$ kids $(P=0.04)$ compared to their nontreated siblings. Anatomically, this rather small pouch is the first rumen area immediately following the end of the esophagus and was characterized by very dense, long, tongue-like, and dark-colored papillae compared to the rest of the rumen wall (Figure 6). Visually, papillae from the ventral rumen and dorsal blind sac were very similar in appearance (shorter and rounded, laying in roof tile formation), whereas papillae from ventral blind sac appeared less developed and bud-like compared to the other sampled areas, in all four experimental conditions. Papillae were small and seemed like they recently developed, hence only small tongue-like papillae were present. In the ruminal atrium, papillae base width of $\mathrm{K}+$ kids $(P=0.06)$ and in particular of $\mathrm{D}+\mathrm{K}+$ kids $(P=0.08)$ tended to be smaller. Papillae length tended or was smaller in the ventral rumen and dorsal blind sac of $\mathrm{K}+$ kids ( $P=0.08, P=0.02$, respectively), but not different in ruminal atrium or ventral blind sac. Total papillae surface area (TSA) was not different between the four experimental conditions in any of the four areas. 


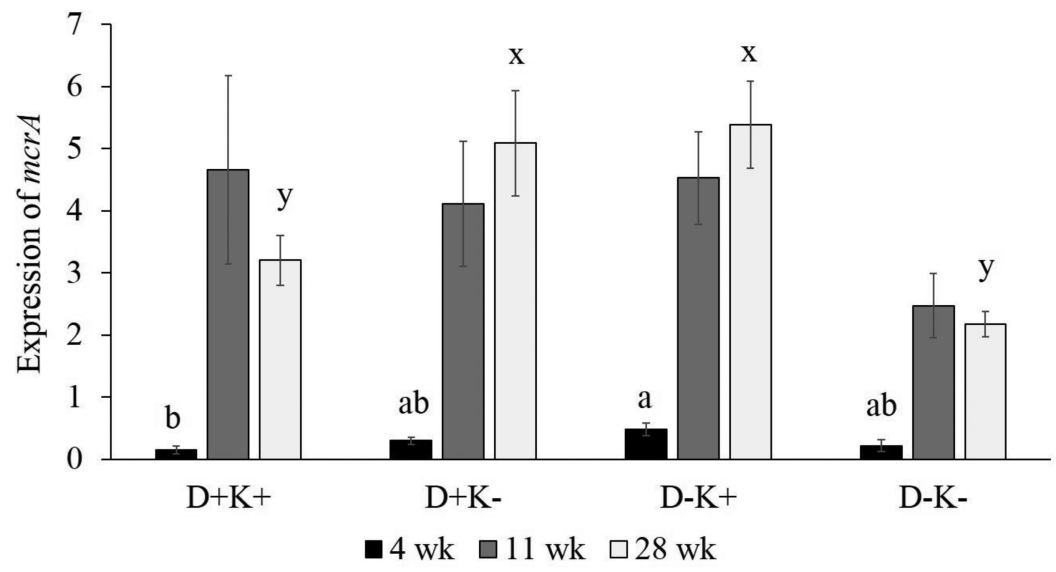

Figure 5. Expression levels of the $m c r A$ gene in rumen methanogens. Mean Calibrated Normalized Relative Quantities (CNRQ) values per experimental group are presented and error bars represent SEs. Means with different letters differ $(P<0.05)$

Table 8. Rumen weight and papillae histomorphometric parameters at 28 wks old

\begin{tabular}{|c|c|c|c|c|c|c|c|}
\hline \multirow[b]{2}{*}{ Item } & \multicolumn{4}{|c|}{ Treatments* } & \multirow[b]{2}{*}{ SEM } & \multicolumn{2}{|c|}{$P$ value } \\
\hline & $\mathrm{D}+$ & $\mathrm{D}-$ & $\mathrm{K}+$ & $\mathrm{K}-$ & & Prenatal treatment & Postnatal treatment \\
\hline Empty rumen weight, $\mathrm{kg}$ & 0.642 & 0.618 & 0.610 & 0.650 & 0.0199 & 0.44 & 0.05 \\
\hline Rumen/BW, \% & 1.96 & 1.98 & 1.98 & 1.96 & 0.046 & 0.67 & 0.64 \\
\hline \multicolumn{8}{|c|}{ Papillae density, number $/ \mathrm{cm}^{2}$} \\
\hline Ruminal atrium & 58.2 & 63.3 & 64.9 & 56.7 & 3.36 & 0.27 & 0.04 \\
\hline Ventral rumen & 58.8 & 60.5 & 59.6 & 59.7 & 3.27 & 0.72 & 0.99 \\
\hline Ventral blind sac & 55.2 & 58.1 & 57.1 & 56.2 & 2.72 & 0.49 & 0.74 \\
\hline Dorsal blind sac & 51.5 & 51.9 & 51.6 & 51.9 & 2.57 & 0.92 & 0.91 \\
\hline \multicolumn{8}{|l|}{ Papillae base width, mm } \\
\hline Ruminal atrium & 0.671 & 0.638 & 0.625 & 0.684 & 0.0243 & 0.34 & 0.06 \\
\hline Ventral rumen & 0.547 & 0.568 & 0.568 & 0.547 & 0.0133 & 0.28 & 0.25 \\
\hline Ventral blind sac & 0.566 & 0.591 & 0.586 & 0.571 & 0.0206 & 0.44 & 0.45 \\
\hline Dorsal blind sac & 0.593 & 0.556 & 0.580 & 0.569 & 0.0203 & 0.23 & 0.68 \\
\hline \multicolumn{8}{|l|}{ Papillae length, mm } \\
\hline Ruminal atrium & 3.05 & 3.08 & 2.98 & 3.15 & 0.144 & 0.88 & 0.45 \\
\hline Ventral rumen & 1.50 & 1.50 & 1.39 & 1.60 & 0.084 & 1.00 & 0.08 \\
\hline Ventral blind sac & 1.05 & 1.10 & 1.05 & 1.09 & 0.068 & 0.61 & 0.59 \\
\hline Dorsal blind sac & 1.57 & 1.52 & 1.46 & 1.63 & 0.062 & 0.62 & 0.02 \\
\hline \multicolumn{8}{|c|}{ Total surface area ${ }^{\dagger}, \mathrm{mm}^{2} / \mathrm{cm}^{2}$} \\
\hline Ruminal atrium & 237 & 244 & 244 & 236 & 15.5 & 0.75 & 0.72 \\
\hline Ventral rumen & 92.1 & 99.1 & 93.5 & 97.7 & 8.07 & 0.53 & 0.55 \\
\hline Ventral blind sac & 65.1 & 74.3 & 68.5 & 71.0 & 5.17 & 0.24 & 0.16 \\
\hline Dorsal blind sac & 93.4 & 85.9 & 85.5 & 93.8 & 4.23 & 0.22 & 0.75 \\
\hline
\end{tabular}

*Treatments consisted of four combinations of pre $(\mathrm{D}+$ or $\mathrm{D}-)$ and/or postnatal $(\mathrm{K}+$ or $\mathrm{K}-$ ) treatment. Since interaction effects between $\mathrm{D}$ and $\mathrm{K}$ were not significant, only main effects are presented. Number of kids per treatment: $\mathrm{D}+\mathrm{K}+(n=10), \mathrm{D}+\mathrm{K}-(n=9), \mathrm{D}-\mathrm{K}+(n=10)$, $\mathrm{D}-\mathrm{K}-(n=10)$.

Total surface area was determined as length $\times$ width $\times 2 \times$ papillae density.

\section{DISCUSSION}

In this study, we tested whether it is possible to reduce enteric $\mathrm{CH}_{4}$ production as well as abundance and activity of methanogenic archaea in the rumen of goat kids by supplementing CO MCFA in EL, and whether these effects can persist after supplementation stops (EL programming). In vitro $\mathrm{CH}_{4}$ production from inoculum of the goat kids was used as a proxy to assess the effect on potential $\mathrm{CH}_{4}$ production. Furthermore, effects on BW, DMI, as well as rumen papillae morphometry (at $28 \mathrm{wk}$ old) were investigated.

\section{Changes in Rumen Microbiota Leading to Differences in In Vitro Fermentation Parameters}

The lack of rumen protozoa at all ages, irrespective of experimental treatment, is striking. To 


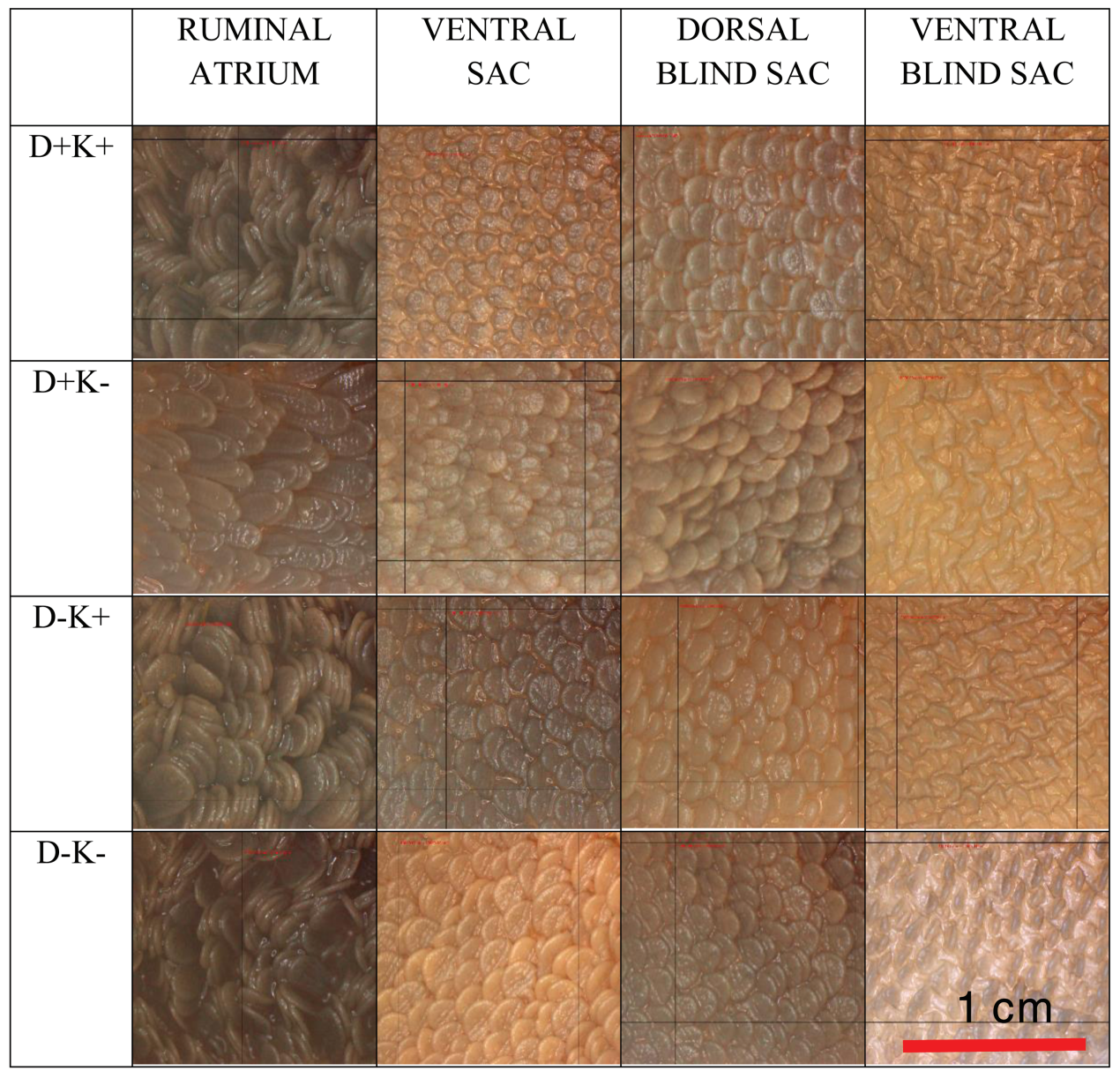

Figure 6. Representative pictures of each rumen area within each experimental condition. Number of kids per treatment: $\mathrm{D}+\mathrm{K}+(n=10)$, $\mathrm{D}+\mathrm{K}-(n=9), \mathrm{D}-\mathrm{K}+(n=10), \mathrm{D}-\mathrm{K}-(n=10)$. The bottom part of the ruminal atrium is characterized by long, tongue-like papillae. The bottom, central part of the ventral sac, and caudal part of the dorsal blind sac resemble each other most, with shorter and rounder papillae laying in a roof tile formation. The papillae of the caudal part of the ventral blind sac appeared to be less developed and bud-like; however, the density was not different from the ventral sac or dorsal blind sac.

verify that this observation was not a result of analytical errors, a number of positive control samples were added to the qPCR assay (i.e. DNA from rumen fluid of 1-, 4-, and 6-mo-old calves, prepared using the same extraction protocol). These tests confirmed the assay was indeed capable of quantifying the protozoal rrs gene in rumen fluid of young ruminants. Additionally, the primers used in the current study have already successfully been used for protozoal quantification in goat kids (Abecia et al., 2014), lambs (Belanche et al., 2010), and cattle (Boeckaert et al., 2007). Probably this observation is an unintended side-effect of the rearing conditions in this trial. Indeed, several studies have shown that lambs and goat kids reared in isolation from adult ruminants have no or much less rumen protozoa compared to animals that have contact with older, faunated ruminants (Faichney et al., 1999; Abecia et al., 2014). Although CO is known to have strong negative effects on rumen protozoal numbers in adult, faunated ruminants (Machmüller et al., 1998; Dohme et al., 1999), defaunation of the prenatally and postnatally supplemented kids could not be attributed to CO MCFA supplementation used in this trial, since the control kids $(\mathrm{D}-\mathrm{K}-$ ) were also lacking rumen protozoa at the three ages.

Supplementing CO MCFA in preruminant goat kids led to similar effects on fermentation as for supplementing $\mathrm{CO}$ or MCFA in adult ruminants: a reduction of in vitro $\mathrm{CH}_{4}$ production accompanied by an accumulation of hydrogen, associated with an increase in propionate production at the expense of acetate (Hristov et al., 2009; Patra and $\mathrm{Yu}, 2013)$. Interestingly, these effects were enhanced by prenatal supplementation, but only until $4 \mathrm{wk}$ after birth. The in vitro $\mathrm{CH}_{4}$ reduction and hydrogen accumulation in $\mathrm{D}+\mathrm{K}+$ kids at 4 wk old corresponded to reduced methanogenic abundance and activity (Dong et al., 1997; Machmüller et al., 1998; Dohme et al., 1999). A decrease in $\mathrm{CH}_{4}$ production, associated with a lower methanogenic activity, has been described in sheep fed CO (Machmüller et al., 2003). Furthermore, the reduced fermentative capacity (as measured by tVFA production after $24 \mathrm{~h}$ 
incubation) of $\mathrm{D}+\mathrm{K}+$ kids corresponded to a lower total eubacterial abundance. The latter, in combination with the reduced acetate production, is in line with the high susceptibility of cellulolytic bacteria to MCFA and dietary fat in general (Machmüller et al., 2003; Patra and Yu, 2013).

Despite the fact that $\mathrm{K}+$ kids still received the CO MCFA at 11 wk old, treatment effects had disappeared. This is in contrast to previously mentioned studies, where animals showed effects as long as treatment lasted. In the current trial, initial CO MCFA dose at birth corresponded to a daily dose of ca. $0.53 \mathrm{~g} / \mathrm{kg} \mathrm{BW}$. Given the major detrimental effect of the postnatal supplementation on DMI, growth and in vitro tVFA production as observed at $4 \mathrm{wk}$, the dose was not raised throughout the trial. Accordingly, the supplementation ratio was reduced to a daily dose of ca. $0.10 \mathrm{~g} /$ $\mathrm{kg} \mathrm{BW}$ around weaning. A study in beef heifers, with different levels of $\mathrm{CO}(0 \mathrm{~g} / \mathrm{d}, 125 \mathrm{~g} / \mathrm{d}, 250 \mathrm{~g} / \mathrm{d}$, $375 \mathrm{~g} / \mathrm{d}$ ), showed a linear decrease in $\mathrm{CH}_{4}$ production $(-14 \%,-20 \%,-40 \%$, respectively), and negative effects on DMI and digestibility only for the highest dose, corresponding to a daily supplementation of $0.78 \mathrm{~g} / \mathrm{kg} \mathrm{BW}$ (Jordan et al., 2006). The two lower doses, corresponding to 0.26 and $0.52 \mathrm{~g} /$ $\mathrm{kg} \mathrm{BW}$, did not affect DMI or digestibility. Another study in 11-mo-old Tibetan sheep, supplementing daily $12 \mathrm{~g} \mathrm{CO}$ or $0.48 \mathrm{~g} / \mathrm{kg} \mathrm{BW}$, showed a strong $\mathrm{CH}_{4}$ reduction in vivo $(-61.2 \%)$ and a reduction of methanogen numbers and Fibrobacter succinogenes (Ding et al., 2012), effects also observed by Liu et al. (2011) in 16-wk-old sheep receiving daily ca. $0.52 \mathrm{~g} / \mathrm{kg} \mathrm{BW}(25 \mathrm{~g} / \mathrm{kg}$ concentrate). However, this did not result in negative effects on growth or a reduction of tVFA in these sheep (Liu et al., 2011), as opposed to the goat kids in the current trial. Hence, the major impact on intake and performance of the CO MCFA, supplemented at a daily dose of about $0.5 \mathrm{~g} / \mathrm{kg} \mathrm{BW}$ in the beginning of the current trial, was unexpected. Supplementation of $\mathrm{CO}$ at this dose seemed safe based on former literature observations. The strong effects might be due to the younger age of the newborn preruminant animals used in the current study compared to the adult ruminants of the former studies. Additionally, the unesterified CO MCFA used in the current study might be more readily available than $\mathrm{CO}$, which might have increased microbial toxicity. On the other hand, the lack of treatment effects at $11 \mathrm{wk}$ old in the current trial could be explained by 1) a too low dose and possible dilution effect in the rumen, or 2) through an adaptation effect of the microbiota to the CO MCFA. Indeed, a recent study coupled to the current trial showed that, in vitro, a lower response in $\mathrm{CH}_{4}$ reduction was found when re-supplementing CO MCFA to rumen fluid of goat kids that were previously exposed to this treatment, suggesting possible adaptation (RuizGonzález et al., 2017).

Because no effects were observed at $11 \mathrm{wk}$, it is not surprising there were no (programmed) effects at 28 wk old. Abecia et al. (2013) did succeed in programming lower $\mathrm{CH}_{4}$ emissions in goat kids, supplementing kids and/or their mothers postnatally from birth until 3 mo old with an antimethanogenic compound (bromochloromethane, $30 \mathrm{~g} /$ $\mathrm{kg} \mathrm{BW/d;} \mathrm{Abecia} \mathrm{et} \mathrm{al.,} \mathrm{2013).} \mathrm{The} \mathrm{effects} \mathrm{persisted}$ until 3 mo after supplementation was ceased (particularly in double treated kids). In the current trial, the only effect at $28 \mathrm{wk}$ old was a higher methanogenic activity - assessed by $\operatorname{mcr} A$ expression by RT-qPCR - in the singularly treated kids compared to the double or not supplemented kids, which did not correspond to methanogen abundance nor to the in vitro $\mathrm{CH}_{4}$ production. Perhaps the sampling procedure with rumen samples at one single moment in time, after a night of fasting, was less appropriate for activity assessments.

\section{Effects on Weight Gain}

Additionally, CO MCFA supplementation negatively affected daily gain until 4 wk old, however no prenatal effect was found. It is unlikely that the growth delay in $\mathrm{K}+$ kids results from the effects on fermentation in EL, since the kids were still preruminants at $4 \mathrm{wk}$ of age. More likely nonrumen related effects played a role, such as EL milk replacer and concentrate intake, possibly caused by the irritating effect of the acid supplement ( $\mathrm{pH} 3.23$ at room temperature) on feed intake. Apparently, the $\mathrm{K}+$ kids had not yet catched up in terms of weight gain at the end of the trial, possibly also due to a slower microbial development in the rumen due to the antimicrobial effects of the supplement. As mentioned before, concentrate intake during the indoor stable period of two kids of the $\mathrm{D}-\mathrm{K}+$ group was extremely low compared to the other eight kids in the group, but BW did not deviate from the group mean. This is probably because they compensated reduced concentrate intake by a larger hay consumption (no data on hay intake).

\section{Papillae Development 4 mo After Postnatal Supplementation}

Rumen development is a combination of anatomic development (growth, rumen papillae), 
microbial colonization, and functional achievement (Li et al., 2012; Jiao et al., 2015) which can possibly be influenced by nutritional intervention in EL. Studies have shown that early intake, type and physical form of solid feed (Beharka et al., 1998; Montoro et al., 2013) and, related to this, the development of the microbial ecosystem, influences functional development of the rumen and therefore future animal performance. In short, rumen development is the result of microbial fermentation products and physical stimulation. Higher amounts of rumen VFA, through higher concentrate intake, could lead to more rapid rumen papillae development (Lesmeister et al., 2004; Suárez et al., 2007). Butyrate and propionate are assumed to positively influence papillary development (Sander et al., 1959; Tamate et al., 1962); however, the influence of butyrate is disputed (Zitnan et al., 2005). Studies showed that suboptimal development of the rumen microbiota will negatively affect rumen development but also depress solid feed intake and papillae development (Tamate et al., 1962; Lesmeister et al., 2004). However, total concentrate intake until weaning or for the whole indoor stable period did not differ between kids. Also, tVFA concentrations in nonincubated rumen fluid were not different between treatment groups. On the other hand, the potential tVFA production, as well as individual VFA productions as assessed in vitro, were very different due to the combination of prenatal and postnatal treatment at $4 \mathrm{wk}$ old. However, only postnatal treatment effects were found for papillae measurements. No clear causal relationship can thus be made between VFA in EL and the effects on rumen papillae. Despite the postnatal treatment effects on papillae density and length, the TSA was not different between experimental groups for any of the rumen areas. Since TSA reflects the absorption capacity of the papillae, we do not expect differences in papillary absorbing function between kids. Ragionieri et al. (2016) also supplemented MCFA to calves, however in the milk replacer ( $11 \mathrm{~g} / \mathrm{d}$ or $0.26 \mathrm{~g} / \mathrm{kg} \mathrm{BW} / \mathrm{d}$, from 14 until $56 \mathrm{~d}$ old). They did not find any effects on papillae density, length, width, or TSA at the age of $70 \mathrm{~d}$ old. The method of supplementation in their trial (in milk replacer, delivering MCFA into the abomasum and hence by-passing the rumen) most probably is the reason no effects were observed in the rumen.

Since the rumen epithelium is known to be subjected to continual changes, from regression to proliferation, like the gut lining (Černík et al., 2014), it is remarkable that postnatal treatment effects have not completely disappeared after 4 mo. This suggests that an EL treatment, directly or indirectly, can influence rumen papillary development on the long term. Interestingly, Tamate et al. (1962) suggested that fetal papillary development is influenced by short chain fatty acids from maternal circulation, however no long-term effects of prenatal supplementation were observed in the present study. Next to the chemical stimulation of papillae development, hay provided physical stimulation during the developmental phases of the rumen. Earlier mentioned studies (Beharka et al., 1998; Montoro et al., 2013) indicated differences in forage intake levels (not measured here) might also account for variations in rumen development, which we cannot rule out based on our data.

In conclusion, supplementing CO MCFA both prenatally and postnatally to goat kids effectively reduced potential in vitro $\mathrm{CH}_{4}$ emissions until $4 \mathrm{wk}$ old, by depressing both methanogen and eubacterial abundance. However, the associated negative effects on rumen fermentation and the observed growth delay due to postnatal treatment indicate the initial dose was too high. A lower starting dose combined with step-wise increase of the dose could have led to longer-lasting effects with less negative impact on animal performance. Interestingly, some rumen papillary characteristics were influenced until 4 mo after postnatal treatment, but this did not lead to differences in total absorbing surface area.

\section{SUPPLEMENTARY DATA}

Supplementary data are available at Journal of Animal Science online.

\section{LITERATURE CITED}

Abecia, L., A. I. Martín-García, G. Martínez, C. J. Newbold, and D. R. Yáñez-Ruiz. 2013. Nutritional intervention in early life to manipulate rumen microbial colonization and methane output by kid goats postweaning. J. Anim. Sci. 91:4832-4840. doi:10.2527/jas.2012-6142

Abecia, L., E. Ramos-Morales, G. Martínez-Fernandez, A. Arco, A. I. Martín-García, C. J. Newbold, and D. R. Yáñez-Ruiz. 2014. Feeding management in early life influences microbial colonisation and fermentation in the rumen of newborn goat kids. Anim. Prod. Sci. 54:1449 1454. doi:10.1071/AN14337

Beharka, A. A., T. G. Nagaraja, J. L. Morrill, G. A. Kennedy, and R. D. Klemm. 1998. Effects of form of the diet on anatomical, microbial, and fermentative development of the rumen of neonatal calves. J. Dairy Sci. 81:1946-1955. doi:10.3168/jds.S0022-0302(98)75768-6

Belanche, A., J. Balcells, G. de la Fuente, D. R. Yañez-Ruíz, M. Fondevila, and L. Calleja. 2010. Description of development of rumen ecosystem by PCR assay in milk-fed, weaned and finished lambs in an intensive fattening 
system. J. Anim. Physiol. Anim. Nutr. (Berl). 94:648-658. doi:10.1111/j.1439-0396.2009.00952.x

Böck, P., and B. Romeis. 1989. Mikroskopische technik. München: Urban und Schwarzenberg.

Boeckaert, C., V. Fievez, D. Van Hecke, W. Verstraete, and N. Boon. 2007. Changes in rumen biohydrogenation intermediates and ciliate protozoa diversity after algae supplementation to dairy cattle. Eur. J. Lipid Sci. Technol. 109:767-777. doi:10.1002/ejlt.200700052

Bustin, S. A., V. Benes, J. A. Garson, J. Hellemans, J. Huggett, M. Kubista, R. Mueller, T. Nolan, M. W. Pfaffl, G. L. Shipley, et al. 2009. The MIQE guidelines: minimum information for publication of quantitative real-time PCR experiments. Clin. Chem. 55:611-622. doi:10.1373/ clinchem.2008.112797

Černík, J., L. Pavlata, A. Pechová, L. Mišurová, O. Jokverová, J. Luňáček, and R. Halouzka. 2014. Effects of peroral supplementation of different forms of zinc on the ruminal mucosa of goat kids - a morphometric study. Acta Vet. Brno, AVB. 82:399-403. doi:10.2754/avb201382040399

De Barbieri, I., R. S. Hegarty, C. Silveira, L. M. Gulino, V. H. Oddy, R. A. Gilbert, A. V. Klieve, and D. Ouwerkerk. 2015a. Programming rumen bacterial communities in newborn Merino lambs. Small Rumin. Res. 129:48-59. doi:10.1016/j.smallrumres.2015.05.015

De Barbieri, I., R. S. Hegarty, C. Silveira, and V. H. Oddy. 2015b. Positive consequences of maternal diet and post-natal rumen inoculation on rumen function and animal performance of Merino lambs. Small Rumin. Res. 129:37-47. doi:10.1016/j.smallrumres.2015.05.017

Denman, S. E., N. W. Tomkins, and C. S. McSweeney. 2007. Quantitation and diversity analysis of ruminal methanogenic populations in response to the antimethanogenic compound bromochloromethane. FEMS Microbiol. Ecol. 62:313-322. doi:10.1111/j.1574-6941.2007.00394.X

Ding, X., R. Long, Q. Zhang, X. Huang, X. Guo, and J. Mi. 2012. Reducing methane emissions and the methanogen population in the rumen of Tibetan sheep by dietary supplementation with coconut oil. Trop. Anim. Health Prod. 44:1541-1545. doi:10.1007/s11250-012-0103-7

Dohme, F., A. Machmüller, B. L. Estermann, P. Pfister, A. Wasserfallen, and M. Kreuzer. 1999. The role of the rumen ciliate protozoa for methane suppression caused by coconut oil. Lett. Appl. Microbiol. 29:187-192. doi:10.1046/j.1365-2672.1999.00614.x

Dong, Y., H. D. Bae, T. A. McAllister, G. W. Mathison, and K.-J. Cheng. 1997. Lipid-induced depression of methane production and digestibility in the artificial rumen system (RUSITEC). Can. J. Anim. Sci. 77:269-278. doi:10.4141/ A96-078

Faichney, G. J., N. M. Graham, and D. M. Walker. 1999. Rumen characteristics, methane emissions, and digestion in weaned lambs reared in isolation. Aust. J. Agric. Res. 50:1083-1090. doi:10.1071/ar98195

Finlay, B. J., G. Esteban, K. J. Clarke, A. G. Williams, T. M. Embley, and R. P. Hirt. 1994. Some rumen ciliates have endosymbiotic methanogens. FEMS Microbiol. Lett. 117:157-161. doi:10.1111/j.1574-6968.1994.tb06758.x

Gadeyne, F., G. Van Ranst, B. Vlaeminck, E. Vossen, P. Van der Meeren, and V. Fievez. 2015. Protection of polyunsaturated oils against ruminal biohydrogenation and oxidation during storage using a polyphenol oxidase containing extract from red clover. Food Chem. 171:241-250. doi:10.1016/j.foodchem.2014.08.109
Gerber, P. J., H. Steinfeld, B. Henderson, A. Mottet, C. Opio, J. Dijkman, A. Falcucci, and G. Tempio. 2013. Tackling climate change through livestock - A global assessment of emissions and mitigation opportunities. Rome: Food and Agriculture Organization of the United Nations (FAO).

Gundersen, H. J. G. 1977. Notes on the estimation of the numerical density of arbitrary profiles: the edge effect. J. Microsc. 111:219-223. doi:10.1111/j.1365-2818.1977.tb00062.x

Hassim, H., M. Lourenço, G. Goel, and V. Fievez. 2010. Effect of different inclusion levels of oil palm fronds on in vitro rumen fermentation pattern, fatty acid metabolism and apparent biohydrogenation of linoleic and linolenic acid. Anim. Feed Sci. Technol. 162:155-158. doi:10.1016/j. anifeedsci.2010.09.011

Hellemans, J., G. Mortier, A. De Paepe, F. Speleman, and J. Vandesompele. 2007. Qbase relative quantification framework and software for management and automated analysis of real-time quantitative PCR data. Genome Biol. 8:R19. doi:10.1186/gb-2007-8-2-r19

Hook, S. E., K. S. Northwood, A. D. Wright, and B. W. McBride. 2009. Long-term monensin supplementation does not significantly affect the quantity or diversity of methanogens in the rumen of the lactating dairy cow. Appl. Environ. Microbiol. 75:374-380. doi:10.1128/AEM.01672-08

Hristov, A. N., M. Vander Pol, M. Agle, S. Zaman, C. Schneider, P. Ndegwa, V. K. Vaddella, K. Johnson, K. J. Shingfield, and S. K. Karnati. 2009. Effect of lauric acid and coconut oil on ruminal fermentation, digestion, ammonia losses from manure, and milk fatty acid composition in lactating cows. J. Dairy Sci. 92:5561-5582. doi:10.3168/jds.2009-2383

Jami, E., A. Israel, A. Kotser, and I. Mizrahi. 2013. Exploring the bovine rumen bacterial community from birth to adulthood. ISME J. 7:1069-1079. doi:10.1038/ismej.2013.2

Jiao, J., X. Li, K. A. Beauchemin, Z. Tan, S. Tang, and C. Zhou. 2015. Rumen development process in goats as affected by supplemental feeding v. Grazing: age-related anatomic development, functional achievement and microbial colonisation. Br. J. Nutr. 113:888-900. doi:10.1017/ S0007114514004413

Jordan, E., D. K. Lovett, M. Hawkins, J. J. Callan, and F. P. O'Mara. 2006. The effect of varying levels of coconut oil on intake, digestibility and methane output from continental cross beef heifers. Animal Sci. 82:859-865. doi:10.1017/ASC2006107

Lesmeister, K. E., P. R. Tozer, and A. J. Heinrichs. 2004. Development and analysis of a rumen tissue sampling procedure. J. Dairy Sci. 87:1336-1344. doi:10.3168/jds. S0022-0302(04)73283-X

Li, R. W., E. E. Connor, C. Li, R. L. Baldwin Vi, and M. E. Sparks. 2012. Characterization of the rumen microbiota of pre-ruminant calves using metagenomic tools. Environ. Microbiol. 14:129-139. doi:10.1111/j.1462-2920.2011.02543.x

Liu, H., V. Vaddella, and D. Zhou. 2011. Effects of chestnut tannins and coconut oil on growth performance, methane emission, ruminal fermentation, and microbial populations in sheep. J. Dairy Sci. 94:6069-6077. doi:10.3168/ jds.2011-4508

Machmüller, A. 2006. Medium-chain fatty acids and their potential to reduce methanogenesis in domestic ruminants. Agric. Ecosyst. Environ. 112:107-114. doi:10.1016/j. agee.2005.08.010

Machmüller, A., D. A. Ossowski, M. Wanner, and M. Kreuzer. 1998. Potential of various fatty feeds to reduce methane release from rumen fermentation in vitro (Rusitec). 
Anim. Feed Sci. Technol. 71:117-130. doi:10.1016/ S0377-8401(97)00126-0

Machmüller, A., C. R. Soliva, and M. Kreuzer. 2003. Effect of coconut oil and defaunation treatment on methanogenesis in sheep. Reprod. Nutr. Dev. 43:41-55. doi:10.1051/ rnd:2003005

Malhi, M., H. Gui, L. Yao, J. R. Aschenbach, G. Gäbel, and Z. Shen. 2013. Increased papillae growth and enhanced short-chain fatty acid absorption in the rumen of goats are associated with transient increases in cyclin D1 expression after ruminal butyrate infusion. J. Dairy Sci. 96:76037616. doi:10.3168/jds.2013-6700

Montoro, C., E. K. Miller-Cushon, T. J. DeVries, and A. Bach. 2013. Effect of physical form of forage on performance, feeding behavior, and digestibility of holstein calves. J. Dairy Sci. 96:1117-1124. doi:10.3168/jds.2012-5731

Newbold, C. J., and D. G. Chamberlain. 1988. Lipids as rumen-defaunating agents. Proc. Nutr. Soc. 47:154A.

Ovreås, L., L. Forney, F. L. Daae, and V. Torsvik. 1997. Distribution of bacterioplankton in meromictic lake saelenvannet, as determined by denaturing gradient gel electrophoresis of PCR-amplified gene fragments coding for 16S rRNA. Appl. Environ. Microbiol. 63:3367-3373. doi:0099-2240/97/\$04.0010

Patra, A. K., and Z. Yu. 2013. Effects of coconut and fish oils on ruminal methanogenesis, fermentation, and abundance and diversity of microbial populations in vitro. J. Dairy Sci. 96:1782-1792. doi:10.3168/jds.2012-6159

Pfaffl, M. W. 2001. A new mathematical model for relative quantification in real-time RT-PCR. Nucleic Acids Res. 29:e45. doi:10.1093/nar/29.9.e45

Popova, M., C. Martin, and D. P. Morgavi. 2010. Improved protocol for high-quality co-extraction of DNA and RNA from rumen digesta. Folia Microbiol. (Praha). 55:368-372. doi:10.1007/s12223-010-0060-3

Ragionieri, L., A. Cacchioli, F. Ravanetti, M. Botti, A. Ivanovska, R. Panu, F. Righi, A. Quarantelli, and F. Gazza. 2016. Effect of the supplementation with a blend containing short and medium chain fatty acid monoglycerides in milk replacer on rumen papillae development in weaning calves. Ann. Anat. 207:97-108. doi:10.1016/j. aanat.2016.04.035

Rey, M., F. Enjalbert, S. Combes, L. Cauquil, O. Bouchez, and V. Monteils. 2014. Establishment of ruminal bacterial community in dairy calves from birth to weaning is sequential. J. Appl. Microbiol. 116:245-257. doi:10.1111/ jam. 12405
Ruiz-González, A., S. Debruyne, J. Jeyanathan, L. Vandaele, S. De Campeneere, and V. Fievez. 2017. Polyunsaturated fatty acids are less effective to reduce methanogenesis in rumen inoculum from calves exposed to a similar treatment early in life. J. Anim. Sci. 95:4677-4686. doi:10.2527/jas2017.1558

Sander, E. G., R. G. Warner, H. N. Harrison, and J. K. Loosli. 1959. The stimulatory effect of sodium butyrate and sodium propionate on the development of Rumen Mucosa in the young calf. J. Dairy Sci. 42:1600-1605. doi:10.3168/ jds.S0022-0302(59)90772-6

Suárez, B. J., C. G. Van Reenen, N. Stockhofe, J. Dijkstra, and W. J. Gerrits. 2007. Effect of roughage source and roughage to concentrate ratio on animal performance and rumen development in veal calves. J. Dairy Sci. 90:2390 2403. doi:10.3168/jds.2006-524

Sylvester, J. T., S. K. Karnati, Z. Yu, M. Morrison, and J. L. Firkins. 2004. Development of an assay to quantify rumen ciliate protozoal biomass in cows using real-time PCR. J. Nutr. 134:3378-3384. doi:10.1093/ jn/134.12.3378

Tamate, H., A. D. McGilliard, N. L. Jacobson, and R. Getty. 1962. Effect of various dietaries on the anatomical development of the stomach in the calf1. J. Dairy Sci. 45:408 420. doi:10.3168/jds.S0022-0302(62)89406-5

Vlaeminck, B., T. Braeckman, and V. Fievez. 2014. Rumen metabolism of $22: 6 n-3$ in vitro is dependent on its concentration and inoculum size, but less dependent on substrate carbohydrate composition. Lipids 49:517-525. doi:10.1007/s11745-014-3905-8

Weimer, P. J. 2015. Redundancy, resilience, and host specificity of the ruminal microbiota: implications for engineering improved ruminal fermentations. Front. Microbiol. 6:296. doi:10.3389/fmicb.2015.00296

Yáñez-Ruiz, D. R., L. Abecia, and C. J. Newbold. 2015. Manipulating rumen microbiome and fermentation through interventions during early life: a review. Front. Microbiol. 6:1133. doi:10.3389/fmicb.2015.01133

Yáñez-Ruiz, D. R., B. Macías, E. Pinloche, and C. J. Newbold. 2010. The persistence of bacterial and methanogenic archaeal communities residing in the rumen of young lambs. FEMS Microbiol. Ecol. 72:272-278. doi:10.1111/j.1574-6941.2010.00852.x

Zitnan, R., S. Kuhla, P. Sanftleben, A. Bilska, F. Schneider, M. Zupcanova, and J. Voigt. 2005. Diet induced ruminal papillae development in neonatal calves not correlating with rumen butyrate. Vet. Med.-Czech. 50:472-479. doi:10.17221/5651-VETMED 